\title{
Update S3-Leitlinie Intestinale Motilitätsstörungen: Definition, Pathophysiologie, Diagnostik und Therapie. Gemeinsame Leitlinie der Deutschen Gesellschaft für Gastroenterologie, Verdauungs- und Stoffwechselkrankheiten (DGVS) und der Deutschen Gesellschaft für Neurogastroenterologie und Motilität (DGNM)
}

Juni 2021 - AWMF-Registriernummer: 021-018

Autoren

Jutta Keller ${ }^{1}$, Thilo Wedel ${ }^{2}$, Holger Seidl ${ }^{3}$, Martin E. Kreis ${ }^{4}$, Ivo van der Voort ${ }^{5}$, Maximilian Gebhard ${ }^{6}$, Jost Langhorst ${ }^{7}$, Petra Lynen Jansen ${ }^{8}$, Oliver Schwandner ${ }^{9}$, Martin Storr ${ }^{10}$, Pia van Leeuwen ${ }^{8}$, Viola Andresen ${ }^{1}$, Jan C. Preiß ${ }^{11}$, Peter Layer ${ }^{1}$ Collaborators:

H. Allescher, T. Andus, S. C. Bischoff, S. Buderus, M. Claßen, U. Ehlert, S. Elsenbruch, M. Engel, A. Enninger, W. Fischbach, M. Freitag, T. Frieling, A. Gillessen, M. Goebel-Stengel, J. Gschossmann, F. Gundling, S. Haag, W. Häuser, U. Helwig, S. Hollerbach, G. Holtmann, M. Karaus, M. Katschinski, H. Krammer, W. Kruis, R. Kuhlbusch-Zicklam, P. Lynen Jansen, A. Madisch, H. Matthes, S. Miehlke, H. Mönnikes, S. Müller-Lissner, B. Niesler, C. Pehl, D. Pohl, C. Posovszky, M. Raithel, G. Röhrig-Herzog, R. Schäfert, M. Schemann, A. Schmidt-Choudhury, S. Schmiedel, A. Schweinlin, J. Schwille-Kiuntke, A. Stengel, J. Tesarz, W. Voderholzer, G. von Boyen, J. von Schönfeld in Zusammenarbeit mit:

Deutsche Gesellschaft für Allgemeinmedizin und Familienmedizin (DEGAM), Deutsche Gesellschaft für Allergologie und Klinische Immunologie (DGAKI), Deutsche Gesellschaft für Allgemein- und Viszeralchirurgie (DGAV), Deutsche Gesellschaft für Ernährungsmedizin (DGEM), Deutsche Gesellschaft für Geriatrie (DGG), Deutsche Gesellschaft für Innere Medizin (DGIM), Deutsche Gesellschaft für Naturheilkunde (DGNHK), Deutsche Gesellschaft für Pathologie und Bundesverband deutscher Pathologen e. V. (DGP/BDP), Deutsche Gesellschaft für Psychosomatische Medizin und Ärztliche Psychotherapie (DGPM), Deutsche Gesellschaft für Verhaltensmedizin und Verhaltensmodifikation (DGVM), Deutsche Schmerzgesellschaft e. V., Deutsches Kollegium für Psychosomatische Medizin (DKPM), Deutsche Gesellschaft für Tropenmedizin und Internationale Gesundheit (DTG), Gesellschaft für Pädiatrische Gastroenterologie und Ernährung (GPGE), Deutsche Gesellschaft für Kinder- und Jugendmedizin (DGKJ), Swiss Society of Neurogastroenterology and Motility (SwissNGM), Informationsforum für Patient:innen mit Magen-Darm-Erkrankungen (MAGDA)

Institute

1 Medizinische Klinik, Israelitisches Krankenhaus in Hamburg, Hamburg, Deutschland

2 Institut für Anatomie, Christian-Albrechts-Universität Kiel, Kiel, Deutschland

3 Klinik für Gastroenterologie, Hepatologie und Gastroenterologische Onkologie, Isarklinikum München, München, Deutschland

4 Klinik für Allgemein-, Viszeral- und Gefäßchirurgie, Charité, Campus Benjamin Franklin, Berlin, Deutschland

5 Klinik für Innere Medizin - Gastroenterologie und Diabetologie, Jüdisches Krankenhaus Berlin, Deutschland

6 Gemeinschaftspraxis Pathologie, Hamburg, Deutschland

7 Klinik für Integrative Medizin und Naturheilkunde, Klinikum Bamberg, Bamberg, Deutschland

8 Deutsche Gesellschaft für Gastroenterologie, Verdauungsund Stoffwechselkrankheiten, Berlin, Deutschland
9 Abteilung für Proktologie, Krankenhaus Barmherzige Brüder, Regensburg

10 Zentrum für Endoskopie, Gesundheitszentrum Starnberger See, Starnberg

11 Klinik für Innere Medizin - Gastroenterologie, Diabetologie und Hepatologie, Klinikum Neukölln, Berlin

Schlüsselwörter

Reizdarm, Intestinale Motilität, Obstipation, Diarrhoe

eingereicht 09.07 .2021

akzeptiert 14.09.2021

Bibliografie

Z Gastroenterol 2022; 60: 192-218

DOI 10.1055/a-1646-1279

ISSN $0044-2771$

(C) 2022. Thieme. All rights reserved.

Georg Thieme Verlag KG, Rüdigerstraße 14,

70469 Stuttgart, Germany 
Korrespondenzadresse

PD Dr. med. Jutta Keller

Medizinische Klinik

Israelitisches Krankenhaus, Orchideenstieg 14,

22297 Hamburg, Deutschland

Tel.: +49/40/511255040

j.keller@ik-h.de
Prof. Dr. med. Peter Layer

Medizinische Klinik

Israelitisches Krankenhaus, Orchideenstieg 14,

22297 Hamburg, Deutschland

Tel.: +49/40/511255001

p.layer@ik-h.de

\begin{tabular}{|l|l|}
\hline Inhaltsverzeichnis & Seite \\
\hline Abkürzungsverzeichnis & 193 \\
\hline Einführung und Methodik & 193 \\
\hline Hintergrund und Ziele & 193 \\
\hline Grundlagen der Methodik & 194 \\
\hline Redaktioneller Hinweis & 197 \\
\hline Besonderer Hinweis & 197 \\
\hline Definitionen, Pathophysiologie und Histopathologie & 198 \\
\hline Enterische Neuropathien & 198 \\
\hline Enterische Myopathien & 199 \\
\hline Enterische Neuro-Gliopathien und Mesenchymopathien & 199 \\
\hline (Differential-)Diagnostik & 202 \\
\hline Therapie & 207 \\
\hline Literatur & 214 \\
\hline
\end{tabular}

$\begin{array}{ll}\text { ABKÜRZUNGSVERZEICHNIS } \\ \text { ACPO } & \begin{array}{l}\text { akute kolonische Pseudoobstruktion, } \\ \text { syn. Ogilvie-Syndrom }\end{array} \\ \text { CED } & \begin{array}{l}\text { chronisch entzündliche Darmerkrankung } \\ \text { chronische intestinale Pseudoobstruktion }\end{array} \\ \text { CIPO } & \begin{array}{l}\text { Cytomegalie-Virus } \\ \text { CMV }\end{array} \\ \text { EBV } & \text { Ebstein-Barr-Virus } \\ \text { EGC } & \text { enterische Glia-Zellen (engl. cells) } \\ \text { ENS } & \text { enterisches Nervensystem } \\ \text { GIT } & \text { Gastrointestinaltrakt } \\ \text { ICC } & \text { interstitielle Cajal-Zellen (engl. cells) } \\ \text { IMC } & \text { idiopathisches Megakolon/-rektum } \\ \text { NTC } & \text { Normal Transit Constipation, engl. } \\ \text { SIBO } & \text { Small Intestinal Bacterial Overgrowth, engl. } \\ \text { STC } & \text { Slow Transit Constipation, engl. }\end{array}$

\section{Einführung und Methodik}

\section{Hintergrund und Ziele}

Leichtere intestinale Motilitätsstörungen sind außerordentlich häufig und betreffen allein in Deutschland Millionen von Menschen entweder transient im Rahmen akuter gastrointestinaler
Infekte oder chronisch, zum Beispiel im Rahmen eines Reizdarmsyndroms. Schwere chronische intestinale Motilitätsstörungen als Ursache gastrointestinaler Beschwerden sind zwar viel seltener, können aber mit erheblichen diagnostischen und therapeutischen Problemen verbunden sein und die Lebensqualität der Betroffenen stark beeinträchtigen.

Die Schwierigkeiten in der Diagnostik sind teilweise dadurch bedingt, dass die infrage kommenden Krankheitsbilder wenig bekannt und manche nach internationaler Literaturlage nicht eindeutig definiert sind. Hinzu kommt, dass aufwendigere diagnostische Verfahren wie intraluminale Motilitätsmessungen, die bei einem Teil dieser Patienten erforderlich sind, nur an wenigen Kliniken etabliert sind. Die Therapie intestinaler Motilitätsstörungen wird nicht nur durch mangelnde Kenntnisse beeinträchtigt, sondern zusätzlich dadurch, dass es kaum Prokinetika gibt, die an Dünn- und Dickdarm wirken. Umso wichtiger wäre der sinnvolle Einsatz der verfügbaren medikamentösen und sonstigen therapeutischen Optionen.

Vor diesem Hintergrund wurde die vorliegende S3-Leitlinie zu intestinalen Motilitätsstörungen erarbeitet und aktualisiert. Ziel dieser Leitlinie ist es, den aktuellen Kenntnisstand zu Pathophysiologie, Diagnostik und Therapie von Motilitätsstörungen des Dünnund Dickdarms zusammenzufassen, zu bewerten und in praxisrelevante Empfehlungen zu übertragen. Die Leitlinie bezieht sich vorwiegend auf Motilitätsstörungen bei Erwachsenen. Besonderheiten, die bei Kindern zu beachten sind, wurden an vielen Stellen, aber nicht durchgehend systematisch bearbeitet.

Für die spezielle Einschätzung gastroenterologischer Probleme bei Diabetes mellitus verweisen wir zusätzlich auf die Nationale VersorgungsLeitlinie „Neuropathie bei Diabetes im Erwachsenenalter" (AWMF-Register-Nr.: nvl-001e) [1]. Die S2k-Leitlinine „Neurogene Darmfunktionsstörung bei Querschnittslähmung“ (AWMF-Register-Nr.: 179-004) behandelt spezifische Fragestellungen bei dieser Patientengruppe.

Die vorliegende Leitlinie richtet sich an die an Diagnostik und Therapie beteiligten Berufsgruppen (Allgemeinmediziner, Internisten, Pathologen, Chirurgen etc.) ebenso wie an betroffene Patienten und an Leistungserbringer (Krankenkassen, Rentenversicherungsträger). Sie soll der evidenzbasierten Fort- und Weiterbildung dienen und auf dieser Basis eine Verbesserung der medizinischen Versorgung der Patienten in der ambulanten und stationären Versorgung erreichen. 


\section{Federführende Fachgesellschaften}

Deutsche Gesellschaft für Gastroenterologie, Verdauungs- und Stoffwechselkrankheiten (DGVS)

Deutsche Gesellschaft für Neurogastroenterologie \& Motilität (DGNM)

\section{Versorgungsbereich}

Die Leitlinie gilt vorwiegend für erwachsene Patienten mit intestinalen Motilitätsstörungen sowohl für die ambulante als auch für die stationäre medizinische Versorgung und behandelt Diagnostik und Therapie in der hausärztlichen und der fachärztlichen Versorgung.

\section{Anwenderzielgruppe/Adressaten}

Die Leitlinie richtet sich an alle Ärzte, die Patienten mit intestinalen Motilitätsstörung versorgen oder an der Versorgung dieser Patienten beteiligt sind, insbesondere an Allgemeinmediziner, Internisten, Gastroenterologen, Chirurgen und Pathologen.

\section{Zusammensetzung der Leitliniengruppe: Beteiligung von Interessengruppen}

Die Leitlinie wurde federführend durch die Deutsche Gesellschaft für Gastroenterologie, Verdauungs- und Stoffwechselkrankheiten (DGVS) gemeinsam mit der Deutschen Gesellschaft für Neurogastroenterologie \& Motilität (DGNM) erstellt, die als Koordinatoren Frau PD Dr. Jutta Keller, Hamburg, und Herrn Prof. Dr. Peter Layer, Hamburg, beauftragten. Methodisch verantwortlich war Herr Dr. Jan Preiß, Berlin. Frau PD Dr. Petra Lynen Jansen und Frau Pia van Leeuwen, DGVS Geschäftsstelle, unterstützen die Leitlinienerstellung organisatorisch. Frau Dr. Nothacker, Arbeitsgemeinschaft der Wissenschaftlichen Medizinischen Fachgesellschaften e. V. (AWMF), Berlin, stand zur methodischen Beratung zur Seite und moderierte als neutrale Leitlinienexpertin die Konsensuskonferenz. Eric Wohlfarth, Torsten Karge und Paul Freudenberger standen für das Leitlinienportal zur Verfügung.

Das Leitlinienvorhaben wurde in der Zeitschrift für Gastroenterologie ausgeschrieben und auf der Webseite der AWMF veröffentlicht, sodass weitere Fachgesellschaften/Vertreter sich zur Mitarbeit melden konnten. Die für das Fachgebiet relevanten Fachgesellschaften und Patientengruppen wurden angeschrieben und um die Nennung von Mandatsträgern gebeten ( $\triangleright$ Tab. 1 ).

Die Auswahl der Leitliniengruppe erfolgte vornehmlich auf dem Boden fachlicher Expertise.

Die Erarbeitung der vorliegenden Leitlinie erfolgte parallel zur Erarbeitung der S3-Leitlinie „Definition, Pathophysiologie, Diagnostik und Therapie des Reizdarmsyndroms “ [2]. Dies begründete sich in der zweifachen Aufgabenstellung an die Autoren: einerseits eine eigenständige Leitlinie zu intestinalen Motilitätsstörungen zu erarbeiten, andererseits als Arbeitsgruppe (AG) 3 der Leitliniengruppe Reizdarmsyndrom Empfehlungen zu erstellen, die die Abgrenzung verschiedener Motilitätsstörungen vom Reizdarm betreffen (vgl. Leitlinie Reizdarmsyndrom) [2]. Deshalb arbeitete die Leitliniengruppe stets in enger Absprache mit allen AGs der Leitlinie Reizdarmsyndrom. So konnten Überschneidungspunkte geklärt und zudem Ressourcen und Kommunikationsstrukturen
- Tab. 1 Repräsentativität der Leitliniengruppe: Beteiligte Fachgesellschaften.

- Deutsche Gesellschaft für Verdauungs- und Stoffwechselkrankheiten (DGVS) (Jutta Keller, Peter Layer)

- Deutsche Gesellschaft für Neurogastroenterologie \& Motilität (DGNM) (Viola Andresen, Siegrid Elsenbruch, Jutta Keller, Christian Pehl, Martin Storr)

- Deutsche Gesellschaft für Allgemein- und Familienmedizin (DEGAM) (Michael Freitag)

- Deutsche Gesellschaft für Allergologie und Klinische Immunologie (DGAKI)

(Martin Raithel)

- Deutsche Gesellschaft für Allgemein- und Viszeralchirurgie (DGAV) (Martin E. Kreis, Oliver Schwandner)

- Deutsche Gesellschaft für Ernährungsmedizin (DGEM) (Stephan C. Bischoff)

- Deutsche Gesellschaft für Geriatrie (DGG) (Gabriele Röhrig-Herzog)

- Deutsche Gesellschaft für Innere Medizin (DGIM) (Hans-Dieter Allescher, Peter Layer)

- Deutsche Gesellschaft für Naturheilkunde (DGNHK) (Jost Langhorst)

- Deutsche Gesellschaft für Pathologie/Bundesverband deutscher Pathologen e. V. (DGP/BDP) (Maximilian Gebhard)

- Deutsche Gesellschaft für Psychosomatische Medizin und Ärztliche Psychotherapie (DGPM) (Ulrich Cuntz, Hubert Mönnikes)

- Deutsche Gesellschaft für Verhaltensmedizin und Verhaltensmodifikation (DGVM) (Hubert Mönnikes)

- Deutsche Schmerzgesellschaft (DGSS) (Winfried Häuser)

- Deutsches Kollegium für Psychosomatische Medizin (DKPM) (Juliane Schwille-Kiuntke, Jonas Tesarz)

- Deutsche Gesellschaft für Tropenmedizin und Internationale Gesundheit (DTG) (Stefan Schmiedel)

- Gesellschaft für Pädiatrische Gastroenterologie und Ernährung (GPGE) (Stephan Buderus, Martin Claßen, Anjona Schmidt Choundhury) in Abstimmung mit der Deutschen Gesellschaft für Kinder- und Jugendmedizin (DGKJ)

- Swiss Society of Neurogastroenterology and Motility (SwissNGM) (Daniel Pohl)

Repräsentativität der Leitliniengruppe: Beteiligung von Patienten

- MAGDA Patientenforum, Arbeitskreis der Deutschen Gesellschaft für Neurogastroenterologie und Motilität e. V.

(Miriam Goebel-Stengel)

effektiv genutzt werden. Darüber hinaus bildeten sämtliche Mitglieder aller AGs der Leitlinie Reizdarmsyndrom das erweiterte Expertengremium ( $\triangleright$ Tab.2), das im Rahmen des Konsensusprozesses über die erarbeiteten Statements abstimmte und Änderungsvorschläge einbringen konnte.

\section{Grundlagen der Methodik}

Das methodologische Vorgehen ist im Leitlinienreport dargelegt. Dieser ist im Internet z. B. unter https://www.dgvs.de/wissen/leit linien/leitlinien-dgvs/intestinale-motilitaetsstoerungen/ frei verfügbar. 
- Tab. 2 Mitglieder der Kerngruppe Leitlinie Intestinale Motilitätsstörungen und erweitertes Expertengremium.

Kerngruppe Leitlinie Intesti(und AG 3: Abgrenzung Reizdarmsyndrom/Motilitätsstörungen) nale Motilitätsstörungen

\begin{tabular}{l|l}
$\begin{array}{l}\text { Leitung } \\
\text { und Koor- } \\
\text { dination }\end{array}$ & $\begin{array}{l}\text { Jutta Keller } \\
\text { (DGVS, DGNM) } \\
\text { Peter Layer } \\
\text { (DGIM, DGVS) }\end{array}$ \\
\hline Mitglieder & $\begin{array}{l}\text { Maximilian Gebhard } \\
\text { (DGP/BDP) } \\
\text { Martin E. Kreis (DGAV) } \\
\text { Jost Langhorst } \\
\text { (DGNHK) } \\
\text { Oliver Schwandner } \\
\text { (DGAV) } \\
\text { Holger Seidl (DGVS) } \\
\text { Martin Alexander Storr } \\
\text { (DGNM) } \\
\text { Thilo Wedel (Experte) } \\
\text { Ivo van der Voort } \\
\text { (DGVS) }\end{array}$ \\
\end{tabular}

\section{Erweitertes Expertengremium}

Hans-Dieter Allescher

Viola Andresen

Tilo Andus

Stephan C. Bischoff

Stephan Buderus

Martin Claßen

Ulrich Cuntz

Ulrike Ehlert

Sigrid Elsenbruch

Matthias Enge

Axel Enninger

Wolfgang Fischbach

Michael Freitag

Thomas Frieling

Anton Gillesen

Miriam Goebel-Stengel

Jürgen Gschoßmann

Felix Gundling

Sebastian Haag

Winfried Häuser

Ulf Helwig

Stephan Hollerbach

Gerald Holtmann

Michael Karaus

Martin Katschinski

Heiner Krammer

Martin Kreis

Wolfgang Kruis

Rita Kuhlbusch-

Zicklam

Jost Langhorst

Ahmed Madisch
DGIM

DGVS, DGNM

DGVS

DGEM

GPGE

GPGE

DGPM

DGVS

DGVS

DGVS

DGVS

DGVS

DEGAM

DGVS

DGVS

MAGDA

DGVS

DGVS

DGVS

DIVS, DGSS

DGVS

DGVS

DGVS

DGVS

DGVS

DGVS

DGAV

DGVS

DGVS

DGNHK

DGVS
- Tab. 2 (Fortsetzung)

\begin{tabular}{|c|c|}
\hline Harald Matthes & DGVS \\
\hline Stephan Miehlke & DGVS \\
\hline Hubert Mönnikes & DGVM/DGPM \\
\hline $\begin{array}{l}\text { Stefan A. Müller- } \\
\text { Lissner }\end{array}$ & DGVS \\
\hline Beate Niesler & DGVS \\
\hline Christian Pehl & DGNM \\
\hline Daniel Pohl & SwissNGM \\
\hline Carsten Posovszky & DGVS \\
\hline Martin Raithel & DGAKI \\
\hline $\begin{array}{l}\text { Gabriele Röhrig- } \\
\text { Herzog }\end{array}$ & DGG \\
\hline Rainer Schäfert & DGVS \\
\hline Michael Schemann & DGVS \\
\hline $\begin{array}{l}\text { Anjona Schmidt- } \\
\text { Choudhury }\end{array}$ & GPGE \\
\hline Stefan Schmiedel & DTG \\
\hline Oliver Schwandner & DGAV \\
\hline Anna Schweinlin & Expertin \\
\hline $\begin{array}{l}\text { Juliane Schwille- } \\
\text { Kiuntke }\end{array}$ & DKPM \\
\hline Andreas Stengel & DGVS \\
\hline $\begin{array}{l}\text { Martin Alexander } \\
\text { Storr }\end{array}$ & DGNM \\
\hline Jonas Tesarz & DKPM \\
\hline Antje Timmer & DGVS \\
\hline Winfried Voderholzer & DGVS \\
\hline Georg von Boyen & DGVS \\
\hline Jürgen von Schönfeld & DGVS \\
\hline \multicolumn{2}{|c|}{ Methodische Unterstützung } \\
\hline Jan Preis & DGVS \\
\hline Petra Lynen Jansen & DGVS \\
\hline Pia van Leeuwen & DGVS \\
\hline \multicolumn{2}{|l|}{ Unterstützung } \\
\hline \multicolumn{2}{|c|}{ Daniela Menge, Hamburg (redaktionelle Unterstützung) } \\
\hline \multicolumn{2}{|c|}{ Monika Nothacker (AWMF) } \\
\hline
\end{tabular}

\section{Schema der Evidenzbewertung}

Die Literaturbewertung wurde nach der Evidenzklassifizierung des Oxford Centre for Evidence-based Medicine 2009 durchgeführt [3]. Die Details zu Suche, Auswahl und Bewertung der Evidenz sind im Leitlinienreport dargestellt.

Schema der Empfehlungsgraduierung

Bei der Überführung der Evidenzstärke in die Empfehlungsstärke konnte der Empfehlungsgrad gegenüber dem Evidenzgrad aus 


\section{Evidenzgrad}

\section{Empfehlungsgrad}

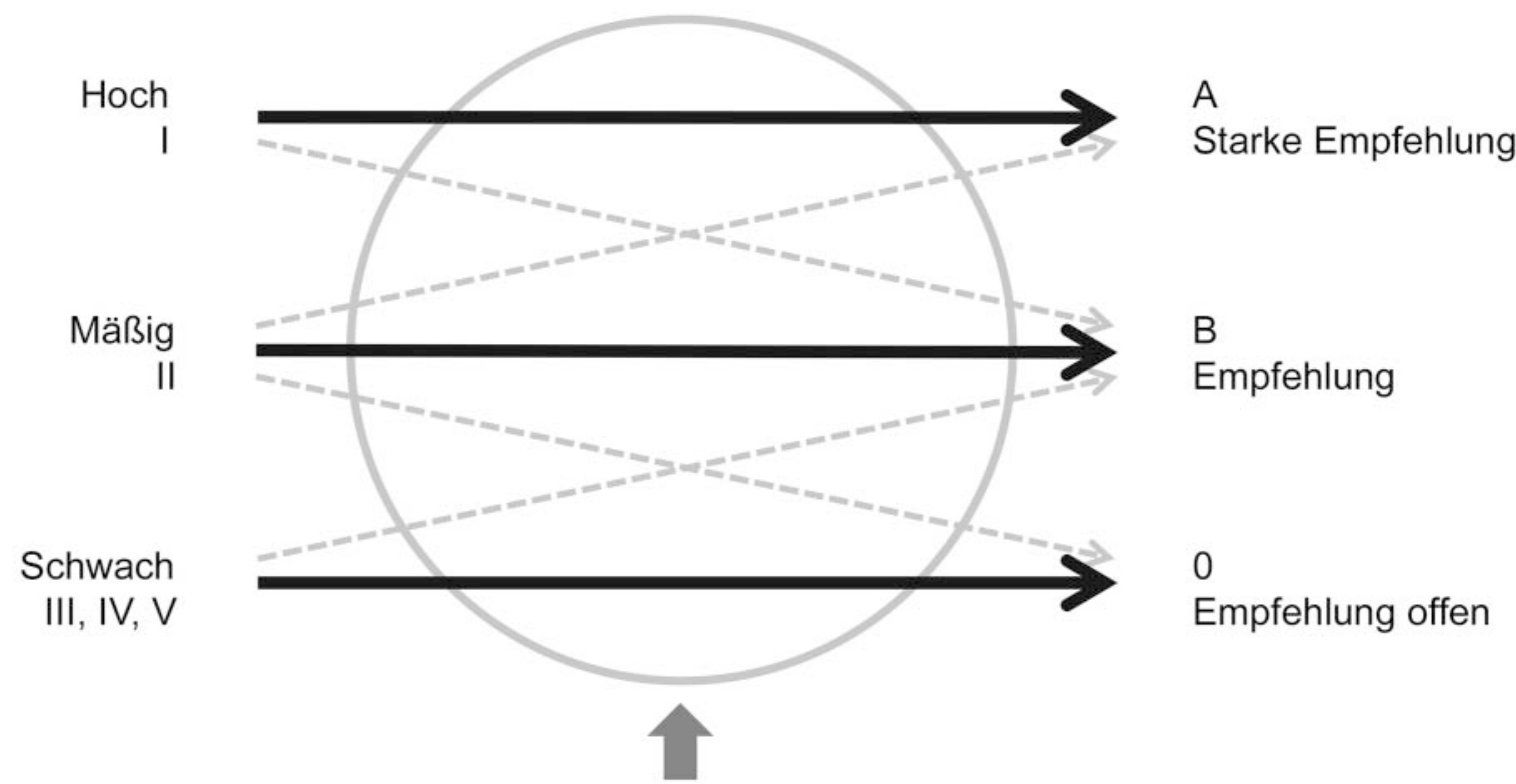

Kriterien für die Graduierung:

- Konsistenz der Studienergebnisse

- Klinische Relevanz der Endpunkte und Effektgrößen

- Nutzen-Risiko-Verhältnis

- Ethische Verpflichtung

- Patientenpräferenz

- Anwendbarkeit, Umsetzbarkeit

- Abb.1 Schema der Empfehlungsgraduierung.

- Tab. 3 Schema zur Graduierung von Empfehlungen.

\begin{tabular}{|l|l|l|}
\hline $\begin{array}{l}\text { Empfehlungsgrad } \\
\text { (nur S3) }\end{array}$ & Beschreibung & Syntax \\
\hline A & starke Empfehlung & soll \\
\hline B & Empfehlung & sollte \\
\hline 0 & offen & kann \\
\hline
\end{tabular}

den in $>$ Abb. 1 angegebenen Gründen auf- oder abgewertet werden. Die Graduierung der Empfehlungen erfolgte außerdem über die Formulierung soll, sollte, kann ( $\vee$ Tab. 3 ).

Die Konsensusstärke wurde gemäß $>$ Tab. 4 festgelegt.

\section{Statements}

Als Statements werden Darlegungen oder Erläuterungen von spezifischen Sachverhalten oder Fragestellungen ohne unmittelbare Handlungsaufforderung bezeichnet. Sie werden entsprechend der Vorgehensweise bei den Empfehlungen im Rahmen eines for-
- Tab. 4 Einteilung der Konsensstärke.

\begin{tabular}{|l|l|}
\hline Konsens & \% Zustimmung \\
\hline Starker Konsens & $>95$ \\
\hline Konsens & $>75-95$ \\
\hline Mehrheitliche Zustimmung & $>50-75$ \\
\hline Kein Konsens & $<50$ \\
\hline
\end{tabular}

malen Konsensusverfahrens verabschiedet und können entweder auf Studienergebnissen oder auf Expertenmeinungen beruhen.

\section{Expertenkonsens}

Als Expertenkonsens werden Empfehlungen bezeichnet, zu denen keine systematische Recherche nach Literatur durchgeführt wurde. Teilweise wurde der Expertenkonsens auch angewandt, wenn nach ausführlicher Recherche keine Literatur vorlag. Diese Empfehlungen adressieren z. T. Vorgehensweisen der guten klinischen Praxis, zu denen keine wissenschaftlichen Studien notwen- 
dig sind bzw. erwartet werden können. Die Stärke der Empfehlung ergibt sich aus der verwendeten Formulierung (soll/sollte/kann) entsprechend der Abstufung in $>$ Tab. 3.

Externe Begutachtung und Verabschiedung Verabschiedung durch die Vorstände der herausgebenden Fachgesellschaften/Organisationen

Im Anschluss an den Peer-Review-Prozess wurde die vollständige Leitlinie von allen beteiligten Fachgesellschaften begutachtet und konsentiert.

Durch die AWMF erfolgte eine externe formale Beurteilung.

Darüber hinaus stand die Leitlinie als Konsultationsfassung zur Kommentierung auf der DGVS- und der AWMF-Website zur Verfügung. Über den DGVS Newsletter wurde um Kommentierung gebeten. Die eingegangenen Anmerkungen bzw. Änderungsvorschläge wurden ausnahmslos geprüft und konnten zum Teil mit in die Endfassung aufgenommen werden. Einzelne besonders umfangreiche Vorschläge werden für die nächste Aktualisierung vorgemerkt. Alle Änderungsvorschläge sind im Supplement dargestellt.

\section{Redaktionelle Unabhängigkeit und Finanzierung der Leitlinie}

Die Aktualisierung der Leitlinie erfolgte in redaktioneller Unabhängigkeit von der finanzierenden Organisation, der DGVS. Die Mittel der DGVS wurden für das CGS-Leitlinienportal zur Durchführung der Delphirunde, zur Erfassung der Interessenkonflikte und zur Literatursammlung und -bewertung sowie für die Konsensuskonferenzen eingesetzt.

Eine finanzielle Beteiligung Dritter erfolgte nicht. Mandatsträger und Experten arbeiteten ausschließlich ehrenamtlich.

\section{Darlegung von und Umgang mit Interessenkonflikten}

Im Einklang mit dem AWMF-Regelwerk zum Umgang mit Interessenkonflikten gaben alle Teilnehmer ihre Interessenkonflikterklärung auf dem entsprechenden AWMF-Formular vor Beginn der Konsensuskonferenz (Formblatt 2010) und erneut im März 2021 (Formblatt 2018) ab (siehe Leitlinienreport, Anhang D). Die Interessenkonflikte wurden von den Koordinatoren der Leitlinie und Frau Nothacker und Frau Lynen gesichtet und nach den Kategorien geringfügig, moderat und hoch bewertet. Hohe Interessenkonflikte mit Bezug zur Leitlinie bestanden bei keinem der Teilnehmer. Als moderat wurden folgende Interessenkonflikte eingestuft:

- Berater- bzw. Gutachtertätigkeit oder bezahlte Mitarbeit in einem wissenschaftlichen Beirat eines Unternehmens der Gesundheitswirtschaft (z. B. Arzneimittelindustrie, Medizinprodukteindustrie), eines kommerziell orientierten Auftragsinstituts oder einer Versicherung

- finanzielle Zuwendungen (Drittmittel) für Forschungsvorhaben oder direkte Finanzierung von Mitarbeitern der Einrichtung vonseiten eines Unternehmens der Gesundheitswirtschaft, eines kommerziell orientierten Auftragsinstituts oder einer Versicherung
- Eigentümerinteresse an Arzneimitteln/Medizinprodukten (z. B. Patent, Urheberrecht, Verkaufslizenz)

- Besitz von Geschäftsanteilen, Aktien, Fonds mit Beteiligung von Unternehmen der Gesundheitswirtschaft

Die Leitliniengruppe entschied einstimmig, dass die von dieser Einschätzung betroffenen Personen sich bei Abstimmungen über ausgewählte Empfehlungen, die von diesen Interessenkonflikten direkt berührt werden könnten, enthalten. Zusätzlich wurden Doppelabstimmungen durchgeführt, die nicht zu einer Veränderung des Ergebnisses führten. Enthaltungen und Doppelabstimmungen sind im Leitlinienreport dargestellt.

Die Beeinflussung durch Interessenkonflikte wurde auch durch die formale Konsensbildung mit externer, unabhängiger Moderation, die interdisziplinäre Erstellung der Leitlinie und die öffentliche Begutachtung reduziert und die Leitlinie vor Verzerrungen und unangemessener Einflussnahme geschützt.

\section{Verbreitung und Implementierung}

\section{Konzept zur Verbreitung und Implementierung}

Die Leitlinie wird in der Zeitschrift für Gastroenterologie, im AWMFLeitlinienportal (www.awmf.de) und auf der Homepage der DGVS (www.dgvs.de) veröffentlicht. Auch eine weitere digitale Verbreitung über Wissensdatenbanken wird angestrebt.

\section{Gültigkeitsdauer und Aktualisierungsverfahren}

Die letzte Überarbeitung dieser Leitlinienaktualisierung erfolgte im März 2021. Die Gültigkeit wird auf 5 Jahre geschätzt (2026). Die Überarbeitung wird durch den Leitlinienbeauftragten der DGVS initiiert werden.

Sollte es zwischenzeitlich wichtige Neuerungen in der Diagnostik und Therapie intestinaler Motilitätsstörungen geben, die eine kurzfristige Aktualisierung notwendig erscheinen lassen, entscheiden die Leitlinienkoordinatoren gemeinsam mit einer Steuergruppe über die Notwendigkeit und die evtl. Inhalte einer Aktualisierung. Diese sollen dann online im Leitlinienportal der AWMF und auf der Homepage der DGVS veröffentlicht werden.

\section{Redaktioneller Hinweis}

\section{Geschlechtsneutrale Formulierung}

Ausschließlich zum Zweck der besseren Lesbarkeit wird auf die geschlechtsspezifische Schreibweise verzichtet. Alle personenbezogenen Bezeichnungen in diesem Dokument sind somit geschlechtsneutral zu verstehen.

\section{Partizipative Entscheidungsfindung}

Alle Empfehlungen der Leitlinie sind als Empfehlungen zu verstehen, die im Sinne einer partizipativen Entscheidungsfindung zwischen Arzt und Patient und ggf. Angehörigen getroffen werden und umzusetzen sind.

\section{Besonderer Hinweis}

Die Medizin unterliegt einem fortwährenden Entwicklungsprozess, sodass alle Angaben, insbesondere zu diagnostischen und therapeu- 
tischen Verfahren, immer nur dem Wissensstand zur Zeit der Drucklegung der Leitlinie entsprechen können. Hinsichtlich der angegebenen Empfehlungen zur Therapie und der Auswahl sowie Dosierung von Medikamenten wurde die größtmögliche Sorgfalt beachtet. Gleichwohl werden die Benutzer aufgefordert, die Beipackzettel und Fachinformationen der Hersteller zur Kontrolle heranzuziehen und im Zweifelsfall einen Spezialisten zu konsultieren. Fragliche Unstimmigkeiten sollen bitte im allgemeinen Interesse der Redaktion mitgeteilt werden. Der Benutzer selbst bleibt verantwortlich für jede diagnostische und therapeutische Applikation, Medikation und Dosierung.

In dieser Leitlinie sind eingetragene Warenzeichen (geschützte Warennamen) nicht besonders kenntlich gemacht. Es kann also aus dem Fehlen eines entsprechenden Hinweises nicht geschlossen werden, dass es sich um einen freien Warennamen handelt.

Das Werk ist in allen seinen Teilen urheberrechtlich geschützt. Jede Verwertung außerhalb der Bestimmung des Urhebergesetzes ist ohne schriftliche Zustimmung der DGVS unzulässig und strafbar. Kein Teil des Werks darf in irgendeiner Form ohne schriftliche Genehmigung reproduziert werden. Dies gilt insbesondere für Vervielfältigungen, Übersetzungen, Mikroverfilmungen und die Einspeicherung, Nutzung und Verwertung in elektronischen Systemen, Intranets und dem Internet.

\section{Definitionen, Pathophysiologie und Histopathologie}

\section{STATEMENT 1 \\ Intestinale Motilitätsstörungen beruhen auf einer neuromus- kulären Dysfunktion von Dünn- und/oder Dickdarm ein- schließlich Rektum. Sie können primär, das heißt ohne ver- ursachende Erkrankung, oder sekundär infolge einer anderen Erkrankung/Störung auftreten. \\ [Starker Konsens]}

\section{Erläuterungen}

Bei den primären Erkrankungen lassen sich in seltenen Fällen genetische Veränderungen nachweisen, die meist sporadisch und seltener familiär auftreten. Zu den Ursachen sekundärer intestinaler Motilitätsstörungen zählen neurologische oder rheumatologische Systemerkrankungen, Autoimmunerkrankungen, toxische, endokrine oder medikamentös induzierte Störungen, Strahlenenteritis, eosinophile Gastroenteritis, Angioödem, Paraneoplasien und postoperative oder postinfektiöse Zustände ( Tab. 5) [4-9].

\section{STATEMENT 2}

Prinzipiell wird pathophysiologisch zwischen intestinalen Neuropathien und Myopathien unterschieden. Mischformen kommen aber ebenfalls vor, und die pathophysiologische Bedeutung sonstiger Strukturen (interstitielle Cajal-Zellen (ICC), enterische Gliazellen) wird zunehmend evident.

[Starker Konsens]
- Tab.5 Ursachen für intestinale Motilitätsstörungen/chronische intestinale Pseudoobstruktion.

\section{Myopathien}

Primäre Myopathien (M. Duchenne, myotone Dystrophie)

Autoimmune Myositis (primär oder bei rheumatologischen Systemerkrankungen)

Mitochondriale Myopathien (z. B. als MNGIE)

Neuropathien

Sporadische oder familiäre enterische Neuropathien (primäre Formen)

Mitochondriale Neuropathien (z. B. MNGIE)

Autoimmune Ganglionitis

- idiopathisch

- paraneoplastisch (z. B. bei kleinzelligem Lungenkarzinom, Thymom, gynäkologischen Tumoren)

- post-/periinfektiös (z. B. Chagas-Erkrankung, CMV, EBV, M. Kawasaki)

- bei anderen Autoimmunerkrankungen, z. B. systemische Sklerose

Toxische Neuropathien (Alkohol/fetales Alkoholsyndrom, Chemotherapeutika und Medikamente, z. B. Vincristin, Diltiazem, Nifedipin)

Endokrine Neuropathien (z. B. bei Diabetes mellitus, Hypoparathyreoidismus, Hypothyreose, Phäochromozytom)

Neurologische Systemerkrankungen (z. B. M. Parkinson, Multiple Sklerose)

Unklare Zuordnung, Misch- und seltene Formen

Ehlers-Danlos-Syndrom

Eosinophile Gastroenteritis

Angioödem

Morbus Crohn

Strahlenenteritis

Multiple endokrine Neoplasie (MEN) 2B mit enterischer

Ganglioneuromatose

\section{Erläuterungen}

Die Motilität von Dünn- und Dickdarm wird maßgeblich durch folgende Zellsysteme innerhalb der Darmwand reguliert: das enterische Nervensystem (ENS), die glatte Muskulatur und die interstitiellen Cajal-Zellen (ICC). Isolierte oder kombinierte Störungen dieser Strukturen können zu klinisch relevanten intestinalen Motilitätsstörungen führen. Allerdings spielt auch die extrinsische Vernetzung zum zentralen Nervensystem eine wichtige regulative Rolle [10], und neuropathische intestinale Motilitätsstörungen werden zwar in den meisten Fällen durch Störungen des ENS verursacht, können aber auch auf Erkrankungen des autonomen und/oder zentralen Nervensystems beruhen [4-6] ( $\triangleright$ Tab. 5).

Die durch eine internationale Expertengruppe erarbeitete „London Klassifikation“ unterteilt die sog. gastrointestinalen neuromuskulären Pathologien in enterische Neuropathien, Myopathien und Mesenchymopathien und ordnet den gastrointestinalen Motilitätsstörungen entsprechende histopathologische Korrelate und Beurteilungskriterien zu [11].

\section{Enterische Neuropathien}

Die funktionelle Integrität der Verdauungsorgane setzt ein komplexes Zusammenspiel von intestinaler Motilität, exo- und 
endokriner Sekretion, Vasomotorik und Mikrozirkulation sowie Immun- und kontrollierten Entzündungsvorgängen voraus. Die Steuerung all der genannten Funktionen obliegt dem ENS, dessen intramurale Nervenplexus im Sinne eines sog. „Brain in the Gut“ in hohem Maße autonom auf Organebene agieren können $[10,12,13]$.

Es verwundert nicht, dass jegliche Veränderung in den komplexen neuronalen Schaltkreisen des ENS zu schweren Veränderungen unter anderem der intestinalen Motilität führen kann [14]. Eine Schädigung des ENS kann primär (idiopathisch) oder sekundär infolge eines breiten Spektrums an Erkrankungen auftreten ( $>$ Tab. 5) $[8,9]$.

Primäre, genetische Ursachen mit der Konsequenz einer Neurodegeneration wurden vor allem für Patienten mit chronischer intestinaler Pseudoobstruktion (CIPO) beforscht. Mehrheitlich ist in diesen Fällen von sporadischen Formen auszugehen, die einer genetischen Diagnostik bisher nicht zugänglich sind [5, 15, 16].

Auch die aus Einzelfallberichten bekannten Gene und Loci bei familiären Formen haben bisher keinen Stellenwert in der Routinediagnostik. Es sind autosomal dominante, autosomal rezessive sowie X-chromosomale Erbgänge bekannt. Folgende mit einer CIPO assoziierte Gene wurden kasuistisch beschrieben: Filamin A (FLNA), Actin G2 (ACTG2), Thymidin Phosphorylase (TYMP), Polymerase gamma (POLG1), Shugoshin-like 1 (SGOL1), Myosin heavy chain 11 (MYH11) und SCO2 (Cytochrome C Oxidase Assembly Protein) $[17,18]$.

Auch der M. Hirschsprung, bei dem es angeboren zu einer segmental kompletten Aganglionose des submukösen und myenterischen Plexus kommt, kann in familiärer Häufung (20\%) oder sporadisch (80\%) auftreten. Die Ursache für diese Störung ist heterogen und wird auf eine unvollständige Besiedlung der Darmwand mit Nervenzellvorläufern aus der Neuralleiste zurückgeführt. Mutationen von Genen, die eine entscheidende Rolle bei dieser neuronalen Migration und Ausreifung spielen, wurden vor allem für RET ( $50 \%$ bei familiärer, $15-20 \%$ bei sporadischer Form) sowie Endothelin-3, Endothelin-B Rezeptor und type1 endothelinconverting enzyme, Transkriptionsfaktoren Sox10 und SMADIP1 und Proto-Onkogenen und deren Liganden (z. B. glial cell-derived neurotrophic factor, Neurturin) beschrieben. Darüber hinaus kann der M. Hirschsprung gehäuft mit anderen Erkrankungen auftreten (in $10 \%$ mit Trisomie 21) und syndromale Formen aufweisen, bei denen zusätzlich Pigment- und Hörstörungen (WaardenburgShah-Syndrom), mentale und motorische Retardierung mit Epilepsie (Mowat-Wilson-Syndrom) oder Respirationsstörungen (Haddad-Syndrom) vorliegen $[17,18]$.

Zu den sekundären Ursachen zählen toxische oder endokrine Neuropathien, neurologische Systemerkrankungen, Strahlenenteritis, eosinophile Gastroenteritis oder Angioödem ( $\vee$ Tab. 5). Die inflammatorisch-neurodegenerative Entität der enterischen Ganglionitis tritt sekundär paraneoplastisch (z. B. bei kleinzelligem Lungenkarzinom, Thymom, Karzinoid, Neuroblastom, Ovarialkarzinom), postinfektiös (z. B. Chagas-Erkrankung, CytomegalieVirus, Ebstein-Barr-Virus, M. Kawasaki) oder bei anderen Autoimmunerkrankungen (z. B. systemische Sklerose) auf, kann aber ebenso ohne nachweisbare Primärerkrankung idiopathisch vorkommen $[6,8,9,19,20]$.
Enterische Ganglionitiden wurden mit zahlreichen Motilitätsstörungen des tubulären Gastrointestinaltrakts, so der Achalasie, Gastroparese, CIPO und „Slow-Transit Constipation“ (STC), in Verbindung gebracht [21].

Enterische Neuropathien können die folgenden histopathologischen Merkmale aufweisen: vollständiger oder partieller Verlust, Hyperplasie, Ektopie, entzündliche oder sekundäre degenerative Schädigungen und Reifungsstörungen von enterischen Nervenzellen sowie Veränderungen der enterischen Gliazellen.

Empfehlungen, wann und wie aussagekräftige Gewebeproben gewonnen, wie sie histologisch untersucht werden sollten, sowie Empfehlungen zur standardisierten Befunderstellung wurden von einer internationalen Expertengruppe erarbeitet. Sie beziehen sich nicht nur auf enterische Neuropathien, sondern auch auf Myopathien, Mesenchymopathien und kombinierte Störungen [22].

\section{Enterische Myopathien}

Viszerale enterische Myopathien sind insgesamt selten. Sie treten überwiegend kongenital (familiär oder sporadisch) auf, häufig mit vakuolärer Degeneration und Verlust von Muskelgewebe der Tunica muscularis und konsekutiver Darmdilatation, nur in Ausnahmefällen mit Hypertrophie und/oder Engstellung des Darms [23]. Oft ist neben mehreren Abschnitten des tubulären Gastrointestinaltrakts auch die Muskulatur der Gallenblase und der harnableitenden Wege betroffen. Auch inflammatorische intestinale Myopathien (enterische Leiomyositiden) sind in der Literatur beschrieben, jedoch basierend auf nur wenigen Fallberichten [24]. Klinisch äußern sich viszerale enterische Myopathien meist mit dem Krankheitsbild der CIPO [23]. Die mitochondriale neurogastrointestinale Enzephalomyopathie (MNGIE) schädigt muskuläre und neuronale Strukturen [25].

Enterische Myopathien können die folgenden histopathologischen Merkmale aufweisen: abnorme Anlage sowie Hypertrophie/Hyperplasie der Muskelschichten, fehlendes bzw. reduziertes Bindegewebsgerüst innerhalb der Tunica muscularis (Desmosis coli), primäre oder sekundäre degenerative sowie entzündliche Schädigungen von glatten Muskelzellen, muskuläre Einschlusskörperchen und Schädigungen des glattmuskulären kontraktilen Apparats [22].

\section{Enterische Neuro-Gliopathien und Mesenchymopathien}

Enterische Glia-Zellen (Enteric Glial Cells, EGC) wurden lange Jahre überwiegend als mechanische Stütz- und Bindekomponente entlang axonaler und innerhalb ganglionärer Strukturen („glia“ abgeleitet aus dem Griechischen „Kleben“) bewertet [26]. Neuere Grundlagenstudien konnten belegen, dass EGC darüber hinaus neben der Regulation intestinaler Entzündungsprozesse für die neuronale Homöostase und die enterische Neurotransmission von Bedeutung sind und damit Einfluss auf die gastrointestinale Motilität haben [27, 28].

Aus klinischer Sicht sind Reduktionen der EGC-Zahl, allein oder gepaart mit Veränderungen enterischer Neurone oder der interstitiellen Cajal-Zellen, bei konservativ unbeherrschbarer STC [29, 30], therapierefraktärer anorektaler Entleerungsstörung [31, 32] oder idiopathischem oder chagasischem Megakolon [33] 
beschrieben - also Krankheitsbildern, bei denen eine schwere Obstipation das führende Symptom darstellt.

Unter den mesenchymalen Zellen der Darmwand gilt den sog. interstitiellen Cajal-Zellen (Interstitial Cells of Cajal, ICC) große Aufmerksamkeit [34, 35]. Als ICC werden unterschiedliche Klassen (u. a. PDGFRa+-Zellen) von in der Darmwandmuskulatur ramifizierten, fibroblastenähnlichen Zellen zusammengefasst, die elektrisch an enterische Muskelzellen gekoppelt sind und ein sog. smooth muscle cell/ICC/PDGFR $\alpha+($ SIP)-Synzytium bilden. Das SIP-Synzytium ist in der Lage, (1) die sog. „Slow-Wave“-Aktivität für die rhythmische Muskelerregung zu generieren (intestinale Schrittmacher), (2) über Neurotransmitter-Rezeptoren nervale Impulse an die Muskulatur zu übertragen (enterische Neurotransmission) sowie (3) mechanosensitive Funktionen auszuüben.

Obwohl ein direkter kausaler Zusammenhang nicht sicher belegt ist, wurde bei vielen intestinalen Motilitätsstörungen eine Reduzierung der ICC-Zahl oder eine veränderte Architektur und Verteilung der ICC-Netzwerke beschrieben, so bei M. Hirschsprung, chronischer Obstipation vom „Slow-Transit“-Typ, Megakolon, Gastroparese, Pylorusstenose, Achalasie und CIPO [34-36].

Als Antwort auf Hypoxie, mechanische Obstruktion oder Entzündungsreiz kann sich die phänotypische Ausprägung der ICC der von Myofibroblasten oder glatten Muskelzellen annähern, nach Normalisierung des Mikroumfelds ist dies reversibel [37].

\section{STATEMENT 3}

Als intestinale Motilitätsstörungen im engeren Sinn etabliert sind die chronische intestinale Pseudoobstruktion (CIPO), die akute kolonische Pseudoobstruktion (ACPO, Ogilvie-Syndrom), das idiopathische Megakolon/-rektum (IMC), der M. Hirschsprung, die „Slow Transit Constipation“ (STC) und anorektale Funktionsstörungen (Beckenbodendyssynergie, Anismus, Beckenbodenspastik).

[Starker Konsens]

\section{Erläuterungen}

CIPO

Die CIPO ist eine schwere intestinale Motilitätsstörung, die intermittierend oder chronisch zu (Sub-)lleussymptomen und entsprechenden Befunden in der bildgebenden Diagnostik führt, ohne dass eine intestinale Obstruktion vorliegt. Die Kombination mit bildgebenden Befunden, die das Vorliegen eines (Sub-)lleuszustands belegen, wird nicht von allen Autoren gefordert, erscheint der Leitliniengruppe aber erforderlich zwecks Abgrenzung gegenüber anderen, weniger schweren Erkrankungen. Die Motilitätsstörungen betreffen bei CIPO vorwiegend den Dünndarm, können sich aber auch an allen anderen Abschnitten des MagenDarm-Trakts und im Bereich anderer Organe (Urogenitaltrakt) manifestieren [4-6]. Die typischen Symptome und die Häufigkeit ihres Vorkommens sind in > Tab. 6 dargestellt [5]. Die histologische Aufarbeitung transmuraler Präparate kann ursächlich enterische Neuropathien, Mesenchymopathien oder Myopathien zeigen, wobei Mischformen nicht selten sind (vgl. Kommentar zu Statement 2) [38]. Für die insgesamt sehr seltene Krank-

- Tab. 6 Symptome bei chronischer intestinaler Pseudoobstruktion (in \% der Patienten) [43].

Überblähung

Abdominelle Schmerzen 75

Übelkeit

Verstopfung

Retrosternales Brennen/Regurgitationen

Völlegefühl

Vorzeitige Sättigung

Erbrechen

Epigastrische Schmerzen/Brennen

Durchfall

Gewichtsverlust

58

49

48

46

44

37

36

34

k.A.

k.A.

k.A. keine Angaben.

heitsentität liegen nur wenige epidemiologischen Daten vor, in der Vielzahl von Fallberichten überwiegt im Erwachsenenalter die Beschreibung von enterischen Neuropathien [6]. In einer landesweiten Befragung aus Japan lag die geschätzte Prävalenz der CIPO bei 0,8-1/100 000 mit einer Inzidenz von 0,21-0,24/ 100000 und einem Durchschnittsalter von 63,1 Jahren für Männer und 59,2 Jahren für Frauen bei Diagnosestellung [39].

Zur Abgrenzung intestinaler Motilitätsstörungen mit abnormen Befunden in der Dünndarmmanometrie, bei denen jedoch keine ileusartigen Episoden auftreten, wird von einigen Autoren der Begriff „enterale Dysmotilität“ benutzt [40]. Dies scheint sinnvoll, der Begriff ist aber nicht allgemein etabliert. Während bei Patienten mit CIPO vorwiegend myopathische bzw. neuromyopathische Veränderungen gefunden wurden, dominierten bei enterischer Dysmotilität inflammatorische Neuropathien [41]. Obwohl pathologische Befunde in der Dünndarmmanometrie häufig von histopathologischen Veränderungen begleitet werden, korrelierten diese nur sehr schlecht mit den spezifischen Manometriemustern (myopathische versus neuropathische Genese) [42]. Dies könnte partiell darauf zurückgeführt werden, dass Fehlfunktionen der intestinalen Muskulatur bzw. des enterischen Nervensystems nicht immer mit histologisch erkennbaren Veränderungen einhergehen müssen.

\section{Akute kolonische Pseudoobstruktion (ACPO, Ogilvie-Syndrom)}

Die ACPO ist charakterisiert durch eine massive Kolondilatation, die sich auf dem Boden einer Motilitätsstörung ohne Vorliegen einer mechanischen Obstruktion im Verlauf weniger Tage entwickelt. Betroffen sind vor allem Patienten mittleren und fortgeschrittenen Alters mit einer Inzidenz von 100/100 000 Krankenhausaufnahmen. Die Mortalitätsrate liegt bei 6,4-9,4\%, in historischen Beschreibungen bei bis zu $30 \%$ [44, 45].

Mit einer ACPO assoziierte Grunderkrankungen können bei ca. 95 \% der Patienten nachgewiesen werden, die idiopathische Form ist selten ( $\triangleright$ Tab. 7) $[44,46]$. Abzugrenzen sind andere Ursachen 
- Tab. 7 Prädisponierende Faktoren und mit ACPO assoziierte Erkrankungen [46].

Inflammatorisch/infektiös: akute Appendizitis, akute Cholezystitis, akute Pankreatitis, Gastritis, Abszess, Sepsis, Herpes-Zoster-Infektion, Pneumonie

Gynäkologisch: normale Schwangerschaft, vaginale Geburt, Kaiserschnitt, Placenta praevia, Hysterektomie

Organtransplantation: Leber, Niere, Herz, Lungen

Urologisch: Nephrolithiasis

Trauma (nicht operativ): Beckentrauma, mechanische Ventilation, Spinalkanaltrauma

Kardiovaskulär/zerebrovaskulär: Myokardinfarkt, kongestive Herzinsuffizienz, Schlaganfall

Metabolisch: Hypokaliämie, Hyponatriämie, Hypo-/Hyperkalzämie, Hypothyreoidismus, Diabetes mellitus, Leberversagen, Niereninsuffizienz, Alkoholabusus

Medikamentös: Antidepressiva, Opiate, Anticholinergika, Benzodiazepine, Phenothiazide, Laxanzienabusus, Kalzium-Kanalblocker, Anti-Parkinson-Medikamente, Amphetamine (Überdosis), zytotoxische Medikamente, Clonidin

Neurologisch: M. Parkinson, M. Alzheimer, Multiple Sklerose

Pulmologisch: COPD

Onkologisch: Kleinzelliges Lungenkarzinom, Multiples Myelom, Leukämie, retroperitoneale Tumoren, disseminierte Beckentumoren

Andere: Verbrennung, gastrointestinale Blutung, retroperitoneales Hämatom, mesenteriale Thrombose, Kraniotomie, Aortenaneurysma, Thorakotomie

Idiopathisch

einer Kolondilatation wie das toxische Megakolon (z. B. bei Clostridium-difficile-Infektion oder bei chronisch entzündlichen Darmerkrankungen) [47]. Die Pathogenese der ACPO ist nicht vollständig verstanden. Vermutlich führen metabolische, retroperitonealoder spinal-traumatische oder pharmakologische Einflüsse zu einer Dysbalance der autonomen Innervation, bei der kontraktilitätsfördernde parasympathische Einflüsse in den Hintergrund gedrängt werden [48].

\section{Idiopathisches Megakolon (IMC)}

Das IMC ist definiert als anhaltende Dilatation eines Kolonsegments, der keine organische Erkrankung zugrunde liegt. Klinische Konsequenz kann eine therapierefraktäre Obstipation sein [49]. Umgekehrt kann sich ein Megakolon auch als Endzustand nach jahrelanger schwerer chronischer Obstipation ausbilden [50]. Anders als beim M. Hirschsprung, der ACPO oder dem sekundären toxischen Megakolon kann keine zugrunde liegende organische Erkrankung gesichert werden [49]. In Ermangelung allgemein anerkannter klinisch-radiologischer Kriterien (häufig wird ein Rektumdurchmesser am Beckeneintritt von 6,5 cm zugrunde gelegt) und pathognomonischer histopathologischer Korrelate bleibt die exakte Prävalenz unklar [21]. Das IMC gilt aber als sehr selten. Gezeigt werden konnten - aber ohne allgemeingültige Stigmata - ursächliche pathologische Veränderungen aller 3 Effektorkom- ponenten der sensomotorischen Darmfunktion, also enterische Neuro-/Myo- und Mesenchymopathien [49].

\section{Hirschsprung}

Der M. Hirschsprung ist durch ein angeboren tonisch kontrahiertes, damit funktionell obstruiertes distales Darmsegment mit konsekutiv massiv prästenotisch dilatiertem Darm charakterisiert. Ursache ist das segmental völlige Fehlen von enterischen Nervenzellen (Aganglionose) im Plexus myentericus und submucosus und damit das Fehlen relaxierender Neurotransmitter [7, 51]. Überwiegend ist das Rektum betroffen, jedoch sind die Manifestation und der Schweregrad der Störung, der u. a. durch die Länge des aganglionären Segments bestimmt wird, variabel [52]. Die Inzidenz des M. Hirschsprung beträgt durchschnittlich 1:5000 Lebendgeburten (1,5:10 000 bei Kaukasiern, 2,8:10 000 bei Asiaten) mit Bevorzugung des männlichen Geschlechts (ca. 3:1). Bei 12\% der Patienten mit M. Hirschsprung können chromosomale Anomalien nachgewiesen werden, darunter ist Trisomie 21 die häufigste chromosomale Erkrankung mit 2-10\% [53].

\section{Epidemiologie der chronischen Obstipation}

Es werden 3 Typen der chronischen Obstipation beschrieben, die sich in ihrer klinischen Präsentation teilweise überlappen können: „Slow Transit Constipation“ (STC), „Normal Transit Obstipation“ und Stuhlentleerungsstörungen. Bezüglich der „Normal Transit Obstipation“ verweisen wir auf die S2k-Leitlinie Chronische Obstipation [54]. Fast alle epidemiologischen Studien differenzieren nicht zwischen den genannten Obstipationstypen. Die globale Prävalenz für chronische Obstipation ist mit ca. 14\% angegeben. In tertiären Referenzzentren sind Stuhlentleerungsstörungen verantwortlich für ein Drittel der Fälle mit chronischer Obstipation. Höhere Prävalenzen liegen vor bei nicht kaukasischer Population, Frauen, Individuen mit niedrigem Einkommen und geringerem Ausbildungsgrad der Eltern sowie bei älteren, hospitalisierten Patienten [55]. In epidemiologischen, „bevölkerungsbasierten“ Untersuchungen lag die nach Alter und Geschlecht korrigierte Prävalenz für Stuhlentleerungsstörungen bei 11/1000 Personen (95\%-KI: 8,7-13,3) mit einer altersunabhängigen Häufung bei Frauen [56, 57].

\section{Slow Transit Constipation (STC)}

Die STC ist charakterisiert durch eine starke, das Krankheitsbild dominierende Verzögerung des Kolontransits (cave: sekundäre Verzögerung des Kolontransits auch bei Stuhlentleerungsstörung möglich), die z. B. durch Markertechniken (Radioisotope oder radioopake Marker) diagnostiziert werden kann [58]. Eine prägnante deutsche Bezeichnung ist für dieses Krankheitsbild nicht etabliert, weshalb wir den englischen Begriff benutzen. Ursachen können enterische Neuro-, Myo- und Mesenchymopathien allein oder als Mischform sein sowie gestörte gastrokolische/kolo-kolische Reflexe [59]. Die Zahl der enterischen Nervenzellen ist häufig vermindert (oligoneuronale Hypoganglionose) [55, 60].

Resultat ist eine verschlechterte propulsive Kolonmotilität, die wiederum auf einer Reduktion der hochamplitudigen, propulsiven Kontraktionen, die Massenbewegungen des Koloninhalts induzieren, beruhen kann. Bei der sog. Kolonparese fehlt die normale 
tonische Kontraktion des Kolons in Antwort auf eine hochkalorische Mahlzeit völlig. Betroffene, häufig junge Frauen, sprechen auf konservative Maßnahmen einschließlich einer hochdosierten Laxanzientherapie meist nicht an [50, 61, 62]. Etliche Patienten mit STC weisen auch Motilitätsstörungen der weiter proximalen Abschnitte des Gastrointestinaltrakts auf (v. a. Dünndarm) [63, 64]. Dies kann für therapeutische Entscheidungen relevant sein [65].

\section{Beckenbodendyssynergie}

Die Beckenbodendyssynergie ist definiert als frustrane oder eingeschränkte Entleerung trotz versuchter Defäkation mit Pressen bei Ausschluss eines mechanischen Entleerungshindernisses, die auf einer willkürlich, aber unbewusst gesteuerten mangelnden Koordination zwischen intrarektaler Druckerhöhung und Relaxation des Sphinkterapparats beruht [62]. Dies führt einerseits zur fehlenden Relaxation oder paradoxer Anspannung des M. sphincter ani und des M. puborectalis [66]. Es resultiert ein unzureichendes Aufrichten und Begradigen des rektoanalen Winkels, sowie Verkürzen und Öffnen des funktionellen Analkanals. Andererseits kann der intrarektale Druckanstieg zu niedrig sein.

In zwei Drittel der erwachsenen Patienten wird die Beckenbodendyssynergie verursacht durch fehlerhafte Toilettengewohnheiten, schmerzhafte Defäkation, obstetrische Verletzungen, Rückenmarkläsionen oder Dysfunktion der sog. „BrainGut“-Achse. Bei dem restlichen Drittel der Patienten liegt ein nicht adäquates Erlernen der Defäkation während der Kindheit vor, häufig verursacht durch Verhaltensstörungen oder ElternKind-Konflikte. Ca. 60 \% der Patienten mit Beckenbodendyssynergie haben auch eine sekundäre STC [56]. Darüber hinaus ist eine Beckenbodendyssynergie in einem Drittel der Fälle mit einer verzögerten Magenentleerung und in zwei Dritteln mit einer rektalen Hyposensitivität assoziiert [55].

Von der Beckenbodendyssynergie abzugrenzen sind die sehr viel selteneren unwillkürlichen, spontanen Kontraktionen des Sphinkterapparats, die als Anismus bezeichnet werden, und die Beckenbodenspastik mit unwillkürlichen, reizgetriggerten Kontraktionen. Diesen beiden Krankheitsbildern liegt jeweils eine nachweisbare extrapyramidale bzw. eine Läsion des ersten Motorneurons zugrunde.

\section{Sekundäre Störungen der intestinalen Motilität}

Störungen der intestinalen Motilität treten sehr häufig im Rahmen akuter Erkrankungen auf, z. B. bei gastrointestinalen Infekten, sind dann aber meist selbstlimitierend und nicht Thema dieser Empfehlungen. Sekundäre unspezifische Störungen von Dünnund Dickdarmmotilität treten in chronischer Form als Folge von Erkrankungen wie Dumping-Syndrom, Gallensäuremalabsorption, Kohlenhydratmalabsorption, bei chronischer Inflammation (z. B. CED) und bakterieller Fehlbesiedlung des Dünndarms (Small Intestinal Bacterial Overgrowth, SIBO) auf (umgekehrt findet sich eine SIBO nahezu regelhaft bei CIPO als Folge der Motilitätsstörung). Klinisch steht dann meist das Symptom Durchfall im Vordergrund. Auch die in $>$ Tab. 6 aufgeführten möglichen Ursachen einer CIPO können mit weniger ausgeprägten sekundären Motilitätsstörungen einhergehen. Darüber hinaus führt eine partielle Obstruktion des Darmlumens (larvierte Obstruktion) zu Änderun- gen der Motilität, teils bevor sich die Obstruktion mithilfe bildgebender Verfahren darstellen lässt [67].

\section{(Differenzial-)Diagnostik}

\section{STATEMENT 4}

Die Symptomatik lässt weder eine sichere Differenzierung zwischen mechanischer Obstruktion und Motilitätsstörung, noch zwischen etablierten Motilitätsstörungen und einem Reizdarmsyndrom zu. Dies gilt insbesondere bei moderaten Beschwerden, die bei den meisten Patienten vorliegen.

[Starker Konsens]

\section{Erläuterungen}

Zu den unspezifischen Symptomen intestinaler Motilitätsstörungen zählen Übelkeit, Erbrechen, abdominelle Schmerzen, Völlegefühl, Blähungen, Diarrhoe und/oder Obstipation. Sofern andere Ursachen ausgeschlossen sind, sprechen isolierte dyspeptische Beschwerden für eine Dysmotilität des oberen Gastrointestinaltrakts (GIT), eine isolierte Obstipation für eine Dysmotilität des unteren GIT. Eine Überlappung der Symptome ist aber häufig und eine exakte Organzuordnung anhand der Symptomatik nicht möglich. Bei schweren intestinalen Motilitätsstörungen kann es infolge einer bakteriellen Überwucherung des Dünndarms (SIBO) und/oder der reduzierten Absorptionskapazität des Darms zu Zeichen der (generalisierten) Malabsorption kommen. Rezidivierendes Erbrechen und/oder chronische Diarrhoen können zu sämtlichen Manifestationen der Exsikkose und des Elektrolytmangels führen. Sonstige extraintestinale Begleitsymptome finden sich vor allem bei Motilitätsstörungen, die im Rahmen einer Systemerkrankung bzw. als Folge anderer Erkrankungen auftreten (z. B. systemische Sklerose, M. Parkinson) [4-6]. Die Schwere der gastrointestinalen Symptome lässt keine zuverlässigen Rückschlüsse auf die zugrunde liegende Ursache zu. Schwerste Beschwerden im Sinne eines akuten Abdomens/lleus sprechen aufgrund der relativen Häufigkeit der Krankheitsbilder in erster Linie für eine mechanische Obstruktion, können aber auch durch eine CIPO hervorgerufen werden.

\section{STATEMENT 5}

Die differenzialdiagnostische Abgrenzung ausgeprägter intestinaler Motilitätsstörungen beispielsweise vom RDS ist bei Ausschluss einer mechanischen Obstruktion anhand der folgenden Kriterien möglich: Ileus- bzw. Subileusepisoden (CIPO), morphologische Veränderungen wie Megakolon und Megarektum, stark verzögerter Kolontransit, Nachweis einer Beckenbodendyssynergie (mit Ansprechen der Symptomatik auf gezielte Therapie), typische histopathologische Befunde (M. Hirschsprung) bzw. ausgeprägte Veränderungen der neuromuskulären intestinalen Strukturen und/oder der manometrisch zu erfassenden Motilitätsmuster.

[Starker Konsens] 


\section{STATEMENT 6}

Bei Patienten mit Verdacht auf eine intestinale Motilitätsstörung als Ursache der Symptomatik soll eine Stufendiagnostik erfolgen mit Laboruntersuchungen, bildgebenden Untersuchungen (Sonografie, Endoskopie, Radiologie), Transitzeitbestimmungen, intraluminalen Manometrien und histologischen Untersuchungen der neuromuskulären Strukturen anhand adäquater Biopsate.

[Expertenkonsens, Konsens]

\section{STATEMENT 7}

Das exakte diagnostische Prozedere (Auswahl und Reihenfolge der Untersuchungen) soll individuell angepasst werden.

[Expertenkonsens, starker Konsens]

\section{STATEMENT 8}

Weitergehende und insbesondere invasive Funktionstests sollen auf Patienten mit Alarmsymptomen oder fehlendem Ansprechen auf übliche therapeutische Maßnahmen beschränkt werden.

[Expertenkonsens, starker Konsens]

\section{Erläuterungen zu Statements 5-8}

Aufgrund der Seltenheit der Krankheitsbilder gibt es keine Studien mit höherem Evidenzgrad, die diagnostische Schemata untersuchen. Die Empfehlungen beruhen demnach auf einem Expertenkonsens. Die angegebenen diagnostischen Empfehlungen entsprechen der sinnvollen klinischen Praxis bei diesen Krankheitsbildern. Erforderlich ist eine Stufendiagnostik, die prinzipiell Laboruntersuchungen, bildgebende Untersuchungen (Sonografie, Endoskopie, Radiologie), Transitzeitbestimmungen, intraluminale Manometrien und histologische Untersuchungen umfassen kann, aber individuell angepasst und auf das Notwendige beschränkt werden soll. Im Allgemeinen gilt:

Bildgebende Untersuchungen (Radiologie/Endoskopie) dienen in erster Linie dem Ausschluss einer mechanischen Obstruktion und sind vorrangig.

Mithilfe von Laboruntersuchungen wird vor allem nach behandelbaren Ursachen schwerer Motilitätsstörungen bzw. nach sekundären Formen und Komplikationen gesucht. Wegen der geringen Invasivität und der möglichen therapeutischen Konsequenzen sollten sie frühzeitig erfolgen.

Motilitätsmessungen im engeren Sinn (Transitzeitbestimmungen oder intraluminale Manometrien) sind indiziert, wenn sich in den vorgenannten Untersuchungen keine wegweisenden Befunde ergeben, wenn es um die Quantifizierung des Ausmaßes (Ausdehnung, Schweregrad) einer Motilitätsstörung oder die Klärung der Pathophysiologie geht. Im Vergleich zu Ösophagus- und anorektalen Manometrien handelt es sich bei Dünndarm- und Kolonma-
- Tab. 8 Indikationen für die Durchführung einer antro-duodenojejunalen Manometrie (in Anlehnung an [69, 70]).

1. Klärung der Diagnose bei unklarer Übelkeit, Erbrechen oder anderen Symptomen, die eine obere gastrointestinale Motilitätsstörung implizieren

2. Differenzierung zwischen myopathischer und neuropathischer Dysfunktion von Magen und/oder Dünndarm

3. Identifizierung einer generalisierten Motilitätsstörung bei Patienten mit Dysmotilität des Kolons (z. B. chronische Obstipation), vor allem vor subtotaler Kolektomie

4. Konfirmation der Diagnose einer CIPO, wenn die Diagnose anhand klinischer und radiologischer und ggf. histopathologischer Kriterien unklar bleibt

5. Suche nach einer möglichen mechanischen Obstruktion bei klinischen Hinweisen, aber fehlendem Nachweis durch bildgebende Untersuchungen

6. Bestimmung, welche Organe transplantiert werden müssen (isolierte vs. multiviszerale Transplantation) bei Patienten mit CIPO, bei denen eine Dünndarmtransplantation vorgesehen ist

7. Bestätigung der Diagnose Rumination (alternativ durch hochauflösende Ösophagusmanometrie + Impedanzmessung möglich)

- Tab.9 Indikationen für die Durchführung einer Kolonmanometrie (in Anlehnung an $[69,70]$ ).

1. Untersuchung von Patienten mit schwerer Obstipation, die nicht auf eine medikamentöse Therapie anspricht und mit einem verzögerten Kolontransit assoziiert ist, ohne dass ein Hinweis auf eine Entleerungsstörung besteht

2. Bestätigung eines chronischen Megakolons oder Megarektums bei Patienten mit Darmdurchmesser $>10 \mathrm{~cm}$ bzw. $15 \mathrm{~cm}$

3. Klärung der Pathophysiologie bei anhaltenden Symptomen nach Entfernung des aganglionären Segments bei Kindern mit M. Hirschsprung

4. Untersuchung der Funktion eines abgeleiteten Kolons vor möglichem Verschluss des Kolostomas

5. Vorhersage der Antwort auf antegrade Einläufe über zökales Stoma

nometrien um aufwendige Untersuchungsverfahren, die nur bei ausgeprägter Symptomatik indiziert sind ( $\triangleright$ Tab. 8, 9).

Eine aussagekräftige histologische Diagnostik erfordert in aller Regel die Untersuchung von tiefen Biopsien (Rektum) bzw. Vollwandbiopsaten durch spezialisierte Laboratorien ( $\triangleright$ Tab. 10-12) [22]. Sie kommt deshalb nur bei schwerer Symptomatik in Betracht.

Manometrische Muster und Ergebnisse einer Ganzwandbiopsie korrelieren neuen Untersuchungen zufolge nur bedingt; etwa drei Viertel der Patienten mit auffälliger Manometrie haben aber eine pathologische Histologie, auch wenn die Biopsie in der Regel nicht aus dem proximalen Dünndarm stammt, der manometrisch untersucht wird [42]. Zudem haben Patienten mit stark verminderter Kontraktilität in der Manometrie eine signifikant verschlechterte Prognose [68].

Ein sinnvolles diagnostisches Vorgehen ist im Folgenden für die einzelnen definierten Motilitätsstörungen beschrieben. 
- Tab.10 Aussagekraft unterschiedlicher Biopsien für die Diagnostik intestinaler Motilitätsstörungen (in Anlehnung an [25]).

\begin{tabular}{|c|c|c|}
\hline Art der Biopsie & Gewinnung & Anwendungsgebiet/Aussagekraft \\
\hline $\begin{array}{l}\text { Konventionelle } \\
\text { Mukosabiopsie }\end{array}$ & Endoskopisch & $\begin{array}{l}\text { Limitiert, da neuromuskuläre Strukturen (insbesondere sub- } \\
\text { muköse und myenterische Ganglien sowie Tunica muscularis) } \\
\text { nicht erfasst werden } \\
\text { Dient vorwiegend dem Ausschluss differenzialdiagnostisch } \\
\text { relevanter Erkrankungen (z. B. Zöliakie) }\end{array}$ \\
\hline Rektale Saugbiopsie & $\begin{array}{l}\text { Endoskopisch, bei älteren Kindern/Erwachsenen } 3 \mathrm{~cm} \\
\text { proximal der Linea dentata } 2-3 \text { Biopsien mit } 3 \mathrm{~mm} \varnothing \\
\text { und } 1 / 3 \text { Submukosa ( } \rightarrow \text { Plexus submucosus erfasst) }\end{array}$ & $\begin{array}{l}\text { Standarddiagnostik des M. Hirschsprung bei Kindern, außer- } \\
\text { dem: (fam.) Erkrankung mit neuronalen (intranukleären) } \\
\text { Einschlüssen, Amyloidose }\end{array}$ \\
\hline Ganzwandbiopsie & $\begin{array}{l}\text { Gewinnung nur invasiv möglich, deshalb prüfen, ob } \\
\text { Präparate von vorangehender Darmresektion vorhan- } \\
\text { den und an Ganzwandbiopsie denken bei Anlage eines } \\
\text { Entlastungsstomas oder OP wegen V. a. mechanische } \\
\text { Obstruktion, sonst: laparoskopische oder laparosko- } \\
\text { pisch assistierte Ganzwandbiopsie an folgenden Stellen: } \\
\text { Magen: } 9 \text { cm proximal des Pylorus, anterior, mittig } \\
\text { zwischen großer und kleiner Kurvatur } \\
\text { Dünndarm: } 1 \text {. gut fassbare Jejunalschlinge bei gene- } \\
\text { ralisierter Erkrankung (ca. } 15 \text { cm distal des Treitz'- } \\
\text { schen Bandes) oder das am stärksten dilatierte } \\
\text { Segment bei lokalisierter Erkrankung } \\
\text { Kolon: Colon descendens bei generalisierter Erkran- } \\
\text { kung oder das am stärksten dilatierte Segment bei } \\
\text { lokalisierter Erkrankung, ggf. durch seromuskuläre } \\
\text { Biopsie } \\
\text { Alternative: endoskopische Ganzwandbiopsie } \\
\text { (Kolon) durch full-thickness resection device (FTRD) }\end{array}$ & $\begin{array}{l}\text { Erforderlich zur histopathologischen Diagnostik der meisten } \\
\text { intestinalen Motilitätsstörungen, da nur bei Ganzwandbiop- } \\
\text { sien die neuromuskulären Strukturen vollständig erfasst } \\
\text { werden } \\
\text { Bezüglich der detaillierten Anwendung und Aussagekraft } \\
\text { vgl. \& Tab.12 }\end{array}$ \\
\hline
\end{tabular}

- Tab.11 Gewinnung und histopathologische Aufarbeitung intestinaler Ganzwandbiopsien (in Anlehnung an [25]).

\begin{tabular}{|l|l|}
\hline Größe & $\begin{array}{l}\text { ca. } 2 \mathrm{~cm} \text { Länge (Schnittfläche), artifizielle Dehnung } \\
\text { bzw. Schrumpfung vermeiden }\end{array}$ \\
\hline Orientierung & $\begin{array}{l}\text { orthogonale Ausrichtung der Darmwandschichten; } \\
\text { Schnittfläche quer zur Darmachse }\end{array}$ \\
\hline Fixierung & $\begin{array}{l}\text { Formalin/Paraformaldehyd zur Paraffin-Einbettung, } \\
\text { ggf. zusätzlich Nativ-Gewebe tieffrieren für Enzym- } \\
\text { histochemie, Glutaraldehyd für Transmissionselek- } \\
\text { tronenmikroskopie (TEM) }\end{array}$ \\
\hline Aufarbeitung & $\begin{array}{l}\text { Schnittdicke: 3-6 } \mu \text { m, Schnitte von 3 unterschiedli- } \\
\text { chen Stellen des Gewebeblocks (Anfang, Mitte, Ende) } \\
\text { anfertigen }\end{array}$ \\
\hline Färbungen & $\begin{array}{l}\text { Histochemie, Immunhistochemie, Enzymhistochemie } \\
\text { (bezüglich Details vgl. — Tab. 12) }\end{array}$ \\
\hline
\end{tabular}

\section{CIPO}

Schwere der Symptomatik und deren Relevanz für Lebensqualität und Prognose rechtfertigen bei Verdacht auf CIPO in aller Regel ausführliche und auch invasive diagnostische Maßnahmen, auch wenn es aufgrund der Seltenheit des Krankheitsbildes nur wenige und fast ausschließlich retrospektive Studien gibt, die untersuchen, welche diagnostischen Verfahren angebracht sind.

Ziele der Diagnostik sind der Ausschluss relevanter Differenzialdiagnosen (mechanische Obstruktion!), die Identifizierung sekundärer Formen, die Aufdeckung der zugrunde liegenden Pathophysiologie und möglicher Komplikationen ( $>$ Tab. 13). Zu diesem Zweck werden die vollständige endoskopische und/oder radiologische Darstellung des GIT empfohlen, die ausführliche Untersuchung von Laborparametern sowie eine gastroduodenojejunale Manometrie (V. a. bei fehlender oder unklarer Histologie). Ein Test zur Erfassung von SIBO als Komplikation einer CIPO sollte ebenfalls durchgeführt werden [71]. Messungen der gastralen und kolonischen Motilität können therapeutisch relevant sein. In Abhängigkeit von der individuellen Symptomatik können auch Motilitätsmessungen an Ösophagus und Anorektum erforderlich sein. Ösophagusmotilitätsstörungen wurden in einer retrospektiven Studie an 116 erwachsenen CIPO-Patienten in 73 \% der Fälle gefunden. Schwere Formen gingen mit Unfähigkeit zur ausreichenden oralen Nahrungsaufnahme, vermehrten Aspirationspneumonien und einem reduzierten Überleben einher [72].

Aussagekräftige histopathologische Untersuchungen erfordern geeignete Biopsate (Ganzwand) und adäquate Untersuchungstechniken, die in der Regel nur von spezialisierten Laboratorien geleistet werden können (vgl. > Tab.10-12). Die sorgfältige histopathologische Diagnostik kann Informationen für das Therapiekonzept liefern [4-6, 22, 69, 71]. Vor allem neurologische, aber auch beispielsweise urologische Zusatzuntersuchungen können zur Aufdeckung sekundärer Formen bzw. der Beteiligung weiterer Organsysteme erforderlich sein. 
- Tab. 12 Diagnostische Kriterien für die histopathologische Klassifizierung intestinaler neuromuskulärer Erkrankungen (nach10)

\begin{tabular}{|c|c|c|c|c|}
\hline Diagnose & QL/QT & Minimum* & Zusatzuntersuchungen & Wichtigste Befunde \\
\hline Aganglionose & QL/QT & H\&E oder EZH & $\begin{array}{l}\text { IHC (Calretinin) } \\
\text { EZH (AChE) }\end{array}$ & $\begin{array}{l}\text { Völliges Fehlen von Neuronen } \\
\text { Hypertrophe submukosale extrinsische } \\
\text { Nervenfasern } \\
\text { fehlende Calretinin-Immunreaktivität }\end{array}$ \\
\hline Hypoganglionose & QL & $\mathrm{H} \& \mathrm{E}$ & IHC (PGP9.5, NSE) $)^{+}$ & Starke Reduktion von Ganglien und Neuronen \\
\hline Ganglioneuromatose & QL & $\mathrm{H} \& \mathrm{E}$ & IHC (PGP9.5, NSE, S100) ${ }^{+}$ & $\begin{array}{l}\text { Hamartomatöse Zunahme von Neuronen und } \\
\text { Ganglien }\end{array}$ \\
\hline IND, Typ B & QT & $\begin{array}{l}\text { EZH (LDH) } \\
\text { IHC }\end{array}$ & IHC (Hu C/D, PGP) & $\begin{array}{l}>8 \text { Neurone in }>20 \% \text { von } 25 \text { submukosalen } \\
\text { Ganglien }\end{array}$ \\
\hline $\begin{array}{l}\text { Degenerative } \\
\text { Neuropathie }\end{array}$ & QL & $\mathrm{H} \& \mathrm{E}$ & & Degeneratives zytologisches Bild \\
\hline $\begin{array}{l}\text { Inflammatorische } \\
\text { Neuropathie }\end{array}$ & $\begin{array}{l}\text { QL } \\
\text { QT }\end{array}$ & $\begin{array}{l}\mathrm{H} \& \mathrm{E} \\
\mathrm{IHC}(\mathrm{CD} 45, \mathrm{CD} 3)\end{array}$ & & $\begin{array}{l}\text { Starke Infiltrate od. Eosinophile } \\
\geq 1 \text { intraganglionäre oder }>5 \text { periganglionäre } \\
\text { Lymphozyten pro Ganglion }\end{array}$ \\
\hline $\begin{array}{l}\text { Abnormale Struktu- } \\
\text { ren in Neuronen }\end{array}$ & QL & $\mathrm{H} \& \mathrm{E}$ & IHC, (SUM01), TEM & $\begin{array}{l}\text { Intraneuronale nukleäre Einschlusskörperchen, } \\
\text { Megamitochondrien }\end{array}$ \\
\hline $\begin{array}{l}\text { Abnormes neuroche- } \\
\text { misches Coding }\end{array}$ & QL/QT & $\begin{array}{l}\mathrm{IHC}^{\$} \\
\mathrm{IHC}\end{array}$ & IHC (PGP9.5, NSE) $)^{+, \S}$ & $\begin{array}{l}\text { Verminderte Immunfärbung im Vergleich zu } \\
\text { Kontrollen } \\
\text { Reduktion einer bestimmten neuronalen } \\
\text { Subpopulation }\end{array}$ \\
\hline Neuronale Unreife & QL & $\mathrm{H} \& \mathrm{E}$ & $\mathrm{EZH}(\mathrm{LDH}, \mathrm{SDH})$ & Morphologisch unreife Neurone \\
\hline $\begin{array}{l}\text { Abnormale enterische } \\
\text { Glia }\end{array}$ & QL & $\mathrm{H} \& \mathrm{E}$ & IHC (S100, GFAP) & Deutliche Zunahme \\
\hline $\begin{array}{l}\text { Fehlbildungen der } \\
\text { Muscularis propria }\end{array}$ & QL, QT & $\mathrm{H} \& \mathrm{E}$ & & Jede Abweichung von 2 Muskelschichten \\
\hline $\begin{array}{l}\text { Degenerative } \\
\text { Leiomyopathie }\end{array}$ & QL & $\mathrm{H} \& \mathrm{E}$ & $\begin{array}{l}\text { Spezialfärbung }{ }^{\&}, \text { IHC, } \\
\text { (SMA), TEM }\end{array}$ & Schädigung und Verlust von Myozyten, Fibrose \\
\hline $\begin{array}{l}\text { Entzündliche } \\
\text { Leiomyopathie }\end{array}$ & QL & $\mathrm{H} \& \mathrm{E}$ & IHC (CD45, CD3) & Infiltrat von Entzündungszellen \\
\hline $\begin{array}{l}\text { Hyperplasie der } \\
\text { Muscularis mucosae }\end{array}$ & QL & $\mathrm{H} \& \mathrm{E}$ & & Verdickte Muscularis mucosae \\
\hline $\begin{array}{l}\text { Abnorme Filament- } \\
\text { proteine }\end{array}$ & QL & IHC (SMA) & & Fehlen von SMA in der zirkulären Muskelschicht** \\
\hline $\begin{array}{l}\text { Muskuläre Einschluss- } \\
\text { körperchen }\end{array}$ & QL, QT & $\begin{array}{l}\text { H\&E } \\
\text { PAS-Färbung } \\
\text { TEM }\end{array}$ & & $\begin{array}{l}\text { glattmuskuläre amphophile M-Körper } \\
\text { glattmuskuläre Polyglucosan-Körper } \\
\text { Megamitochondrien in Myozyten }\end{array}$ \\
\hline Atrophe Desmose & QL & Spezialfärbung\& & & $\begin{array}{l}\text { Totales oder fokales Fehlen des Bindegewebsgerüsts } \\
\text { in Muscularis propria }\end{array}$ \\
\hline $\begin{array}{l}\text { Abnormale } \\
\text { ICC-Netzwerke }\end{array}$ & QT & & $\mathrm{IHC}$ (CD117) IHC (Ano1) & $\begin{array}{l}\text { ICC um }>50 \% \text { reduziert im Vergleich zu } \\
\text { Kontrollschnitten }\end{array}$ \\
\hline
\end{tabular}

CD117 ist synonym mit c-kit; Ano1 ist synonym mit DOG1. AChE: Acetylcholinesterase, EZH: Enzymhistochemie, ICC: interstitielle Cajal-Zellen, GFAP: glial fibrillary acidic protein, IHC: Immunhistochemie, IND: intestinale neuronale Dysplasie, LDH: Laktatdehydrogenase, NSE: neuronspezifische Enolase, PAS: periodic acid-Schiff, PGP9.5: protein gene product 9.5, QL: qualitativ, QT: quantitativ, SDH: Succinatdehydrogenase, SMA: smooth muscle alpha-actin, TEM: Transmissionselektronenmikroskopie.

* bezüglich Anforderungen an Aufarbeitung vgl. > Tab. 11.

+ Allgemeine neurale Marker zum Vergleich (Alternativen: Hu C/D, Neurofilament, PGP 9.5).

\$ bislang nicht definiert, am häufigsten benutzt werden: NO, ChAT, SP, VIP, dies sind aber keine Empfehlungen für die Routinepathologie.

$\S$ panneuronale Marker werden hier benutzt, um festzustellen, ob die absolute Zahl der Neurone reduziert ist.

\& Trichrom-, Van.Giesson- oder Picrosirius-Färbung.

** regional unterschiedlich, dies ist ein normaler Befund im lleum 
- Tab. 13 Diagnostische Verfahren bei V.a. schwere intestinale Motilitätsstörung/CIPO [69, 70, 73].

Bildgebende Untersuchungen: vollständige endoskopische und/oder radiologische Darstellung des Gastrointestinaltrakts (z. B. Ösophagogastroduodenoskopie + lleokoloskopie (jeweils einschließlich Routinehistologie) + (MRT-)Sellink)

Laboruntersuchungen: ausführliche Untersuchung von Routinelaborparametern, die Hinweise auf entzündliche oder tumoröse gastrointestinale Erkrankungen, Malabsorption oder Elektrolytmangel liefern können; außerdem Suche nach sekundären Formen und seltenen Differenzialdiagnosen (in Abhängigkeit von der individuellen Symptomatik) durch Bestimmung von TSH, C1-Esterase-Inhibitor, Porphyriediagnostik, Autoantikörperdiagnostik wie bei V. a. Kollagenose sowie Bestimmung von ANNA-1 bzw. anti-Hu-Autoantikörpern als Hinweis auf eine enterische Ganglionitis

Gastroduodenojejunale Manometrie: zum Beleg gestörter Motilitätsmuster, zur Eingrenzung der Pathophysiologie (Myopathie vs. Neuropathie) bzw. ggf. zur Aufdeckung einer larvierten mechanischen Obstruktion (vgl. > Tab. 8)

Transittests: Magenentleerungsmessung (Szintigrafie, ${ }^{13} \mathrm{C}$-Atemtest), Messung des orozökalen ( $\mathrm{H}_{2}$-Lactulose-Atemtest) bzw. Dünndarmtransits (Szintigrafie, kombinierter $\mathrm{H}_{2}$-Lactulose- und ${ }^{13} \mathrm{C}$-Acetat-Atemtest [74]) und des Kolontransits (röntgendichte Marker, Hinton-Test, Szintigrafie), vor allem zur Quantifizierung von Ausdehnung und Schweregrad der Motilitätsstörung

Tests zur Erfassung einer bakteriellen Fehlbesiedlung: Glucose- $\mathrm{H}_{2}$-Atemtest, ggf. kulturelle Bestimmung der Keimzahl aus Dünndarmaspiraten

Ösophagusmanometrie: bei V. a. bzw. zum Ausschluss einer generalisierten Motilitätsstörung, von besonderer Bedeutung bei zugrunde liegender systemischer Sklerose [75], außerdem prognostisch aussagekräftig (s. o. [72])

Anorektale Manometrie: bei Patienten mit Obstipation (als führendes Symptom) [76]

Kolonmanometrie: bei Patienten mit schwerer Obstipation und V. a. generalisierte Motilitätsstörung [72]

Histopathologie: kann neuromuskuläre Störung belegen und charakterisieren und dadurch Informationen für das Therapiekonzept liefern, erforderlich sind geeignete Biopsate (Ganzwand) und adäquate Untersuchungstechniken [22], die in der Regel nur von spezialisierten Laboratorien geleistet werden können (vgl. — Tab. 10-12).

Erweiterte Diagnostik: v. a. neurologische, ggf. auch endokrinologische oder urologische Zusatzuntersuchungen zur Aufdeckung sekundärer Formen bzw. zusätzlich beteiligter Organsysteme

Für Patienten mit enteraler Dysmotilität wird angenommen, dass ein vergleichbares diagnostisches Prozedere wie bei CIPO mit zurückhaltendem Einsatz invasiver Methoden sinnvoll ist.

\section{ACPO}

Weil das Krankheitsbild in der Regel Patienten mit schwerer Grunderkrankung betrifft und passager ist, spielt die eigentliche Motilitätsdiagnostik allenfalls eine untergeordnete Rolle.

Stattdessen wird die Diagnose anhand des klinischen Bildes vermutet und durch die Abdomenübersichtsaufnahme bestätigt, die ein stark geweitetes Kolon zeigt (Grad unterschiedlich, Differenzialdiagnosen: mechanische Obstruktion, toxisches Megakolon, ischämische Kolitis). Wenn eine mechanische Obstruktion nicht anhand der Gasverteilung ausgeschlossen werden kann, wird zusätzlich ein Abdomen-CT oder ein Kolonkontrasteinlauf mit einem wasserlöslichen Kontrastmittel empfohlen. Generell ist bei diesen Untersuchungen auch auf Zeichen der Perforation und/ oder Peritonitis zu achten.

Darüber hinaus sind Laboruntersuchungen indiziert, um Ursachen und Komplikationen der ACPO zu erfassen (Blutbild, Elektrolyte, Parameter zur Erfassung von Leber-, Nieren- und Schilddrüsenfunktion, Blutkultur bei V.a. septische Komplikationen).

Um die Entwicklung einer kritischen Dilatation und von Komplikationen zu erfassen, wird empfohlen, Abdomenübersichtsaufnahmen und Bluttests bis zur Besserung von klinischem Bild und Befund alle 12-24 h zu wiederholen [77]. Eine vorsichtige Koloskopie bei unvorbereitetem Darm kann diagnostisch (und therapeutisch) indiziert sein, sofern kein Anhalt für eine Peritonitis besteht $[47,78,79]$. Sie ist bei Zeichen der Ischämie abzubrechen.

\section{IMC}

Ein chronisches Megakolon kann so ausgeprägt sein, dass die Diagnose bei klinischen Routineuntersuchungen (Abdomenübersichtsaufnahme, Ileokoloskopie) oder bei Laparotomie offensichtlich ist, exakte diagnostische Kriterien sind nicht allgemein etabliert, es werden aber die folgenden Grenzwerte vorgeschlagen: Kolondurchmesser $>6,5 \mathrm{~cm}$ auf Höhe des Beckenrandes, $>8 \mathrm{~cm}$ im Bereich des Colon ascendens und $>12 \mathrm{~cm}$ im Bereich des Zökums [80]. Ein Megarektum wird klassisch radiologisch gesichert anhand eines rektalen Durchmessers von $>6,5 \mathrm{~cm}$ (Kolon-KE) bzw. > 8,3 cm (konventionelle Defäkografie). Alternativ werden bei der anorektalen Manometrie mithilfe eines einfachen Latexballons die Volumina zur Erreichung der rektalen Sensitivitätsschwellen gemessen [76]. Sind diese bei leerem Rektum normal, ist ein Megarektum ausgeschlossen. Bei auffälligen Befunden bietet die fluoroskopische Messung des rektalen Durchmessers bei minimalem Distensionsdruck (mittels Barostat erzeugt) das vermutlich zuverlässigste diagnostische Verfahren (normal $<6,3 \mathrm{~cm}$ ). Aber auch die alleinige Messung des rektalen bzw. kolonischen Volumens mittels Barostat ist etabliert. Dieses Verfahren zeigt bei Megarektum bzw. -kolon neben einem erhöhten Volumen häufig auch eine erhöhte Compliance des betroffenen Segments $[49,70,76,81]$. Wenn mehr als $300 \mathrm{ml}$ benötigt werden, um einen Druck von $20 \mathrm{mmHg}$ in einem Barostat-Ballon $(10 \mathrm{~cm}$ Länge, Platzierung im linksseitigen Kolon) zu erzeugen, kann die Diagnose Megakolon als gesichert gelten [80].

Ein chronisches Megarektum/Megakolon kann einerseits eine Obstipation verursachen, andererseits aber auch das Endstadium einer schweren Obstipation (STC) aufgrund einer Kolonmotilitätsstörung darstellen. In Abhängigkeit von der individuellen Sympto- 
matik können deshalb auch, wie in $>$ Tab. 13 beschrieben, weitere diagnostische Tests erforderlich sein.

Die Diagnose idiopathisches Megakolon/-rektum erfordert den Ausschluss möglicher Ursachen [49]. Histopathologisch fanden sich bei mehr als der Hälfte von 31 Patienten mit IMC Zeichen der Neuropathie, seltener Myo- oder Mesenchymopathien, Überlappungen kamen vor. Zudem zeigten dilatierte und nicht dilatierte Kolonanteile bei den meisten Patienten ähnliche histopathologische Auffälligkeiten, sodass Letztere der klinischen Manifestation des Megakolons vorauszugehen scheinen [82].

\section{Hirschsprung}

Als Referenzverfahren in der Diagnostik des M. Hirschsprung gilt die Etagenbiopsie des Rektums, die als Saugbiopsie (oder mittels Schere) durchgeführt wird, mit anschließender histopathologischer Untersuchung (Bestimmung der Acetylcholinesterase-Aktivität oder Einsatz immunhistochemischer Verfahren (neuronale Marker)). Zusätzlich werden die anorektale Manometrie und Kolon-Kontrastdarstellungen eingesetzt.

Im Gegensatz zu den meisten anderen intestinalen und kolonischen Motilitätsstörungen liegen für die Diagnostik des M. Hirschsprung systematische Untersuchungen und auch Metaanalysen zur Wertigkeit verschiedener diagnostischer Verfahren vor [83, 84]. Letztere zeigen, dass bei Kindern, die älter als 1 Jahr sind, die rektale Saugbiopsie mit anschließender Untersuchung der Acetylcholinesterase-Aktivität eine Sensitivität von mehr als $90 \%$ und eine nahezu 100 \%ige Spezifität im Vergleich zum Referenzverfahren (Vollwandbiopsie und/oder Beobachtung des klinischen Langzeitverlaufs) hat $[83,84]$. Sensitivität und Spezifität der anorektalen Manometrie sind mit 91 \% bzw. $94 \%$ geringfügig niedriger. Demgegenüber besitzt der Kolon-Kontrasteinlauf nur eine Sensitivität von 70 \% und eine Spezifität von 83 \% für die Diagnose eines M. Hirschsprung in diesem Patientenkollektiv [83]. Er wird deshalb nicht von allen Arbeitsgruppen empfohlen und wenn, dann erst nach Diagnosestellung zur Planung des operativen Vorgehens $[85,86]$. Sowohl die anorektale Manometrie (vor allem bei kleinen Kindern) als auch die Gewinnung einer aussagekräftigen Biopsie und deren histologische Untersuchung erfordern erfahrene Untersucher.

Bei Säuglingen sind die radiologischen Befunde teils unauffällig und auch der Manometrie wird keine sichere Aussagekraft zugesprochen, sodass für die positive Bestätigung der Diagnose M. Hirschsprung Biopsie und Histologie gefordert werden [51]. Generell sollten alle Fälle einer frühkindlichen schweren Obstipation untersucht werden, um einen M. Hirschsprung oder andere Störungen des ENS auszuschließen. Bei positivem Befund sind in diesen Fällen wegen der möglichen Assoziation des M. Hirschsprung mit genetischen Syndromen, die ein erhöhtes onkogenes Potenzial aufweisen, molekulargenetische Untersuchungen auf MEN2A- und MTC-Mutationen indiziert; bei totaler kolonischer Aganglionose wird ein komplettes RET-Screening empfohlen [51].

In den seltenen Fällen, in denen ein M. Hirschsprung erst im Erwachsenenalter diagnostiziert wird, liegt meist ein sehr kurzes aganglionäres Segment vor. Ob die Ergebnisse der oben zitierten systematischen Studien bei Kindern auf Erwachsene zu übertragen sind, ist unklar. Allgemein ist zu fordern, dass ein suspekter radiologischer Befund mittels Manometrie und Histologie bestätigt wird [62]. Weil der manometrische Nachweis eines normalen anorektalen Inhibitionsreflexes das Krankheitsbild ausschließt und diese Untersuchung bei Erwachsenen in aller Regel leicht durchführbar ist, wird die anorektale Manometrie vor eventueller Durchführung einer tiefen Rektumbiopsie empfohlen (Biopsie nur bei fehlendem Nachweis des Reflexes) [76].

\section{Schwere Obstipation (STC und anorektale Funktionsstörungen)}

Ziele der Diagnostik sind der Ausschluss einer mechanischen Obstruktion bzw. organischen Ursache der Obstipation sowie die Differenzierung zwischen Kolontransitstörung (STC), Stuhlentleerungsstörung/Beckenbodendyssynergie und Obstipation bei normalem Kolontransit („Normal Transit Constipation“, NTC). Die Grundlage dafür bilden die ausführliche und gezielte Anamnese (z. B. begünstigende Medikamente?) und die körperliche Untersuchung einschließlich digitaler rektaler Untersuchung (bei Erwachsenen). Wenn nur Studien mit mittlerer oder hoher Qualität berücksichtigt werden, gibt es nur wenig Evidenz für den Nutzen darüber hinausgehender diagnostischer Tests [87]. Dies gilt sowohl für Untersuchungen, die dem Ausschluss organischer Ursachen dienen, als auch für Funktionstests. Deshalb werden weitergehende Untersuchungen von Experten nur bei Patienten mit Alarmsymptomen oder fehlendem Ansprechen auf übliche therapeutische Maßnahmen empfohlen [88]. Sinnvolle diagnostische Verfahren zur Abklärung von Patienten mit STC sind in $>$ Tab. 14 dargestellt.

\section{Therapie}

\section{STATEMENT 9}

Bei Patienten mit CIPO sollen die folgenden Therapieziele angestrebt werden: Aufrechterhaltung eines adäquaten Ernährungsstatus, Verbesserung der intestinalen Propulsion, Linderung abdomineller Symptome sowie Vermeidung bzw. Therapie von Komplikationen (z. B. bakterielle Fehlbesiedlung). [Empfehlungsgrad A, starker Konsens]

\section{STATEMENT 10}

Zur medikamentösen Therapie bei CIPO sollten die in > Tab. 15 genannten Wirkstoffe in Erwägung gezogen werden.

[Empfehlungsgrad B, Konsens]

\section{STATEMENT 11}

Unnötige Laparotomien während pseudoobstruktiver Episoden sollten vermieden werden.

[Empfehlungsgrad B, Konsens] 
- Tab. 14 Diagnostische Verfahren bei schwerer, therapierefraktärer Obstipation [50, 61, 62, 69, 70, 76, 87, 89].

Laboruntersuchungen: Elektrolyte, TSH, PTH, Blutglukose, Nierenfunktionsparameter

Bildgebende Untersuchungen: Abdominalsonografie, lleokoloskopie, ggf. CT(MRT)-Kolonografie

Kolontransitstudien: in der Regel mithilfe röntgendichter Marker (modifizierter Hinton-Test), ermöglicht objektive Messung der Kolontransitzeit (normal < 68-72 h) und bildet Grundlage für Diagnose einer STC (sofern szintigrafische Messung nicht verfügbar), allerdings sekundäre Störung des Kolontransits bei bis zu 2/3 der Patienten mit Stuhlentleerungsstörung/Beckenbodendyssynergie, deshalb immer auch sorgfältige morphologische und funktionelle Untersuchung des Anorektums erforderlich

Anorektale Manometrie: erlaubt den Ausschluss eines M. Hirschsprung (s. o.) und erfasst eine Beckenbodendyssynergie als Ursache einer schweren Obstipation (= mangelnde Koordination zwischen rektalem Druckanstieg und Sphinkterrelaxation beim Pressen), findet sich bei 20-75\% der untersuchten Patienten, allerdings teils eingeschränkte Kooperation und kein ausreichendes Pressen der Patienten unter Laborbedingungen, deshalb Bestätigung durch 2. Verfahren erforderlich, bei Verwendung hochauflösender manometrischer Verfahren hohe Rate an falsch positiven Befunden für Beckenbodendyssynergie bei Gesunden [90, 91]

Defäkografie: konventionelle oder MRT-Defäkografie liefert auffällige Befunde in bis zu 3/4 der Patienten mit Obstipation, erfasst sowohl morphologisch/ anatomische Abnormitäten (z. B. Rektozele, rektale Intussusception) als auch funktionelle Beeinträchtigung, deshalb auch geeignet als bestätigendes Verfahren bei V.a. Beckenbodendyssynergie

Ballonexpulsionstest: untersucht Fähigkeit des Patienten, einen in das Rektum eingeführten wassergefüllten Ballon (meist 50 ml, teils zusätzlich Gewichte) zu evakuieren, einfacher Screeningtest, der ausgeprägtere Stuhlentleerungsstörungen erfasst

Kolonmanometrie: Aufwendige Untersuchung mit meist kombinierter Erfassung der phasischen (Wasserperfusionsmanometrie) und tonischen (Barostat) Kolonmotilität, auch hochauflösende Messverfahren verfügbar, reserviert für Patienten mit schwerster Symptomatik und ohne Anhalt für Stuhlentleerungsstörung, insbesondere vor geplanter Kolektomie (vgl. \ Tab.9)

Untersuchungen der Motilität des oberen GIT: Magenentleerungstests (Szintigrafie, ${ }^{13} \mathrm{C}$-Atemtest), Untersuchung des Dünndarmtransits (Szintigrafie, $\mathrm{H}_{2}$-Lactulose-Atemtest) und antroduodenojejunale Manometrie können erforderlich sein bei V. a. generalisierte Motilitätsstörung, Dünndarmmanometrie notwendig vor subtotaler Kolektomie, da schlechtere Langzeitverläufe bei Patienten mit generalisierter Motilitätsstörung

Erweiterte Diagnostik: v. a. neurologische, ggf. auch endokrinologische Zusatzuntersuchungen zur Aufdeckung sekundärer Formen

\section{STATEMENT 12}

Schmerzen bei Patienten mit CIPO sollten nicht mit Opioiden therapiert werden.

[Empfehlungsgrad B, Konsens]

\section{Erläuterungen zu Statements 9-12}

Größere und vor allem kontrollierte Studien zur Therapie bei Patienten mit CIPO wurden nur sehr begrenzt durchgeführt. Somit beruhen die unten ausgeführten Therapieempfehlungen zur diätetischen, medikamentösen und chirurgischen Therapie vielfach auf einer sehr begrenzten Datenlage oder Expertenmeinung.

\section{Ernährungstherapie}

Die ESPEN-Leitlinien zum chronischen Darmversagen bei Erwachsenen empfehlen keine spezifische Diät für Patienten mit CIPO, sondern die Zusammensetzung der Nahrung nach individueller Verträglichkeit [108]. Eine Verbesserung der Motilität durch diätetische Maßnahmen konnte bei hospitalisierten Patienten mit unterschiedlichen Motilitätsstörungen tatsächlich nicht nachgewiesen werden [92]. Es gibt aber keine gezielten Untersuchungen für CIPO-Patienten, während für Patienten mit Gastroparese die Überlegenheit der sogenannten „small particle diet“ gezeigt wurde [109]. Wegen der häufigen Beteiligung des Magens bei CIPO und der besseren Verträglichkeit sind bei oraler Ernährung mehrere kleine, fettarme und ballaststoffarme Mahlzeiten allgemein zu bevorzugen. Falls erforderlich, sollten die Patienten (zusätzlich)
Trinknährlösungen erhalten. Wenn dies nicht erfolgreich ist, sollte die Möglichkeit einer enteralen Ernährung (nasojejunale Sonde, PEG-J) geprüft werden. Wegen des deutlich höheren Komplikationsrisikos sollte eine dauerhafte (teil)parenterale Ernährung nur bei Versagen der zuvor genannten Optionen erfolgen [4-6, 108].

\section{Prokinetische Therapie}

Die Möglichkeiten zur medikamentösen Verbesserung der intestinalen Propulsion sind limitiert, zumal zurzeit (Stand 2021) in Deutschland nur ein einziger Wirkstoff, nämlich Prucaloprid, als Prokinetikum zugelassen ist. Prucaloprid ist ein 5HT4-Agonist und zugelassen zur Behandlung der laxanzienrefraktären Obstipation [110-112]. Wegen der Verbreitung von 5HT4-Rezeptoren im Bereich des gesamten Gastrointestinaltrakts und in Analogie zur Wirksamkeit der „Vorgängersubstanz“ Cisaprid sind therapeutische Effekte aber auch bei CIPO zu erwarten. Tatsächlich gibt es eine sehr kleine $(\mathrm{N}=4)$, aber kontrollierte Studie, die zeigen konnte, dass die wiederholte, doppelblinde Gabe von Prucaloprid die Symptomatik signifikant gegenüber Placebo verbessert [97].

Eine Metaanalyse randomisierter, kontrollierter Studien belegt, dass die Dopamin-D2-Antagonisten Metoclopramid und Domperidon sowie Makrolide (Erytrhomycin) die Motilität bei Patienten mit unterschiedlichen Motilitätsstörungen bessern [92]. Metoclopramid und Domperidon sind in Deutschland aber nur noch zur Therapie von Übelkeit zugelassen, und ihr Einsatz ist auch in dieser Indikation auf höchstens 5 bzw. 7 Tage beschränkt. Zudem wirken beide Substanzen, so wie die ebenfalls nur off-label einsetzbaren Makrolide, fast ausschließlich gastroduodenal. Weil aber der obere GIT häufig mit betroffen ist, erscheint ein Thera- 
- Tab. 15 Medikamentöse Therapie schwerer intestinaler Motilitätsstörungen.

\begin{tabular}{|c|c|c|}
\hline Wirkstoff bzw. Wirkstoffgruppe & Evidenz & Kommentar \\
\hline Metoclopramid, Domperidon & $\begin{array}{l}\text { Metaanalyse randomisierter kontrollierter Studien mit positiver } \\
\text { Wirkung auf Motilität, allerdings gemischte Patientengruppen mit } \\
\text { höhergradiger Störung (hospitalisiert) [92] } \\
\text { Fallberichte für CIPO-Patienten [93] }\end{array}$ & $\begin{array}{l}\text { Wirkung gastroduodenal, deshalb Thera- } \\
\text { pieversuch vor allem bei gastraler Betei- } \\
\text { ligung sinnvoll }\end{array}$ \\
\hline Erythromycin, Macrolide & $\begin{array}{l}\text { Fallserie an Kindern mit positivem Effekt bei } 3 \text { von } 4 \text { [94] } \\
\text { Interventionsstudie, nicht kontrolliert, offen, an } 15 \text { CIPO-Pat. mit } \\
\text { deutlichem positivem Effekt bei } 6 \text { [95] } \\
\text { Interventionsstudie, nicht kontrolliert, offen, an } 14 \text { CIPO-Pat. in } \\
\text { Kombination mit Octreotid (s. u.), lang anhaltende Besserung von } \\
\text { Übelkeit und Bauchschmerzen bei } 5 \text { [96] }\end{array}$ & $\begin{array}{l}\text { Wirkung gastroduodenal, deshalb Ein- } \\
\text { satz vor allem bei gastraler Beteiligung } \\
\text { sinnvoll }\end{array}$ \\
\hline Prucaloprid & $\begin{array}{l}\text { Sehr kleine randomisierte, kontrollierte Studie }(\mathrm{N}=4) \text {, aber mit } \\
\text { verblindeter und wiederholter Gabe von Placebo/Prucaloprid über } \\
4 \times 12 \text { Wo. bei jedem Pat., signifikante Schmerzreduktion [97] }\end{array}$ & Besserung der Beschwerden \\
\hline Acetylcholinesterase-Inhibitoren & $\begin{array}{l}\text { Fallserie an Kindern, Pyridostigmin bewirkt u. a. Reduktion der } \\
\text { abdominellen Distension und Verbesserung der oralen Nahrungsto- } \\
\text { leranz [98] } \\
\text { Interventionsstudie mit Pyridostigmin, nicht kontrolliert, offen, an } \\
13 \text { Pat. mit STC }(\mathrm{N}=6) \text { oder CIPO }(\mathrm{N}=7) \text { zeigt Verbesserung von der } \\
\text { Darmdistension bei allen CIPO-Pat [99] }\end{array}$ & $\begin{array}{l}\text { Dosierung durch Nebenwirkungen limi- } \\
\text { tiert (in Studie bei erwachsenen CIPO- } \\
\text { Pat. allerdings kaum aufgetreten) [99] }\end{array}$ \\
\hline Octreotid & $\begin{array}{l}\text { Interventionsstudie, nicht kontrolliert, offen an } 16 \text { Kindern mit CIPO } \\
\text { und TPN mit relevanter Verbesserung der enteralen Nahrungstole- } \\
\text { ranz bei } 7 \text { [100] } \\
\text { Interventionsstudie, nicht kontrolliert, offen, an } 14 \text { CIPO-Pat. über } \\
20-33 \text { Wo. unter Therapie mit Octreotid und Erythromycin (s. o.), } \\
\text { vorher und hinterher antroduodenojejunale Manometrie, lang } \\
\text { anhaltende Besserung von Übelkeit und Bauchschmerzen bei } 5 \text { [96] }\end{array}$ & $\begin{array}{l}\text { Klinischer Effekt korreliert mit manome- } \\
\text { trisch nachweisbaren Effekten auf Motili- } \\
\text { tät (Ansprechen prinzipiell vorhersagbar) }\end{array}$ \\
\hline Kortikosteroide, Immunglobuline & $\begin{array}{l}\text { Kohortenstudie an } 61 \text { Pat. mit CIPO bei SLE, } 183 \text { Patienten mit SLE } \\
\text { ohne CIPO, fast alle Patienten mit CIPO sprechen auf Kortikosteroide } \\
\text { an, Rückfall bei ca. } 15 \% \text { mit erneutem gutem Ansprechen auf } \\
\text { Steroide [101] } \\
\text { Kohortenstudie an } 15 \text { Pat. mit therapierefraktärer systemischer } \\
\text { Sklerose und abdomineller Symptomatik, Therapie mit Immunglo- } \\
\text { bulinen i. v. über im Mittel 2,3 J., darunter signifikante Besserung der } \\
\text { GIT-Symptome [102] } \\
\text { Interventionsstudie, nicht kontrolliert, offen, an } 23 \text { Pat. mit vermu- } \\
\text { teter autoimmuner GIT-Motilitätsstörung, Behandlung mit Immun- } \\
\text { globulinen und/oder Methylprednisolon, erfolgreich bei } 17 \text { Pat } \\
\text { [103]. }\end{array}$ & $\begin{array}{l}\text { Größte Erfahrung bei Patienten mit } \\
\text { zugrunde liegender rheumatologischer } \\
\text { Erkrankung (SLE), für andere potenzielle } \\
\text { Indikationen (enterische Ganglionitits, } \\
\text { autoimmune Myositis) nur Fallberichte, } \\
\text { probatorische Behandlung bei V. a. } \\
\text { autoimmunes Geschehen sinnvoll [103] }\end{array}$ \\
\hline Orale $\mu$-Opiat-Rezeptor-Antagonisten & $\begin{array}{l}\text { Metaanalyse randomisierter, kontrollierter Studien mit positivem } \\
\text { Effekt für opiatinduzierte Obstipation [104], keine Studien an } \\
\text { Patienten mit CIPO }\end{array}$ & $\begin{array}{l}\text { In aller Regel nur für Patienten unter } \\
\text { Opioidtherapie, die nach Möglichkeit zu } \\
\text { vermeiden ist, können aber Transit auch } \\
\text { bei opioidnaiven Personen beschleuni- } \\
\text { gen [105] }\end{array}$ \\
\hline $\begin{array}{l}\text { Antibiotika zur Behandlung einer } \\
\text { bakteriellen Fehlbesiedlung des } \\
\text { Dünndarms }\end{array}$ & $\begin{array}{l}\text { Rifaximin in (kleinen) randomisierten, placebokontrollierten } \\
\text { Doppelblind-Studien effektiver als Tetrazyklin oder Metronidazol } \\
\text { für Eradikation und Behandlung von Beschwerden bei SIBO, keine } \\
\text { Studien explizit für CIPO }[106,107]\end{array}$ & $\begin{array}{l}\text { Nahezu immer vorhanden bei CIPO, } \\
\text { rezidiviert sehr häufig }\end{array}$ \\
\hline
\end{tabular}

pieversuch mit diesen Prokinetika trotzdem sinnvoll. Ihr positiver Effekt bei CIPO wird durch Fallserien und einzelne kleine Studien belegt [93-96]. Neostigmin verbessert die intestinale Propulsion signifikant bei ACPO [79, 113], und Cholinergika können auch bei ansonsten therapierefraktären Fällen von CIPO erfolgreich eingesetzt werden $[98,99]$. Ihre Anwendung wird aber durch die bei höherer Dosierung auftretenden Nebenwirkungen limitiert.
Das Somatostatinanalogon Octreotid löst Phase-III-Komplexe aus und hat in kleinen Studien als Monotherapie oder in Kombination mit Erythromycin positive Effekte bei Kindern und Erwachsenen gezeigt $[96,100]$. Die klinische Wirksamkeit korrelierte dabei mit manometrisch nachweisbaren Effekten auf die Motilität, sodass das Ansprechen auf diese aufwendige und teure Therapie prinzipiell vorhersagbar erscheint [96]. 
Metaanalysen belegen, dass orale $\mu$-Opiat-Rezeptor-Antagonisten (peripherally acting $\mu$-opiate receptor antagonist, PAMORA) bei opiatinduzierter Obstipation wirksam sind [104]. Es liegen zwar auch dazu keine gezielten Studien an Patienten mit CIPO vor, wenn bei diesen aber eine Opiattherapie unumgänglich ist (s. u.), erscheint die Kombination mit einem PAMORA primär sinnvoll. Zudem können PAMORA den Transit auch bei opioidnaiven Personen beschleunigen [105], und es gibt entsprechende Fallberichte zur positiven Wirksamkeit bei CIPO [114].

\section{Immunsuppressiva}

Rheumatologische Systemerkrankungen sind eine vergleichsweise häufige Ursache schwerer gastrointestinaler Motilitätsstörungen ( $\triangleright$ Tab. 15). Die immunsuppressive Therapie der Grunderkrankung kann in diesen Fällen auch die Motilitätsstörung bessern. In einer Fall-Kontroll-Studie an insgesamt mehr als 240 Patienten mit systemischem Lupus erythematodes (SLE) sprachen fast alle Patienten mit CIPO ( $N=61)$ auf eine Kortikosteroid-Therapie an. Bei $15 \%$ kam es zu einem Rückfall mit erneutem gutem Ansprechen auf Steroide $[101,115]$. Auch intravenöse Immunglobulingabe kann bei SLE die gastrointestinalen Symptome signifikant bessern [102].

Darüber hinaus wurde in Einzelfällen bei zugrunde liegender enterischer Ganglionitis durch Steroide und/oder Immunsuppressiva eine Verbesserung der Symptomatik und des gastrointestinalen Transits erzielt [19]. Eine enterische Ganglionitis kann allerdings nur anhand von chirurgisch oder endoskopisch zu gewinnenden Vollwandpräparaten diagnostiziert werden [22]. Bislang besteht keine Einigkeit darüber, ob bei erwachsenen Patienten mit CIPO die Indikation zu einem Steroidtherapieversuch großzügig oder nur bei solchen mit nachgewiesener entzündlicher Infiltration des Plexus myentericus gestellt werden sollte. Eine aktuelle Studie zeigt aber, dass etwa drei Viertel der Patienten mit vermuteter autoimmuner enterischer Dysmotilität von einer probatorischen Immuntherapie (überwiegend Immunglobulingabe, sonst Prednison oder Kombination) profitieren [103].

\section{Antibiotika}

Fast alle Patienten mit CIPO weisen aufgrund der massiv eingeschränkten Reinigungsfunktion eine bakterielle Überwucherung des Dünndarms (SIBO) auf. Diese kann die abdominelle Symptomatik wesentlich verschlechtern, Malabsorption verstärken und mit dem Auftreten von Lebererkrankungen oder deren Verschlechterung assoziiert sein, vor allem bei Patienten mit (teil)parenteraler Ernährung [116-118]. Die am besten etablierte SIBO-Therapie besteht in der Gabe des topischen Antibiotikums Rifaximin (3×550 mg über 1014 Tage) [106, 107]. Bei Fortbestehen der Motilitätsstörung ist damit zu rechnen, dass auch nach erfolgreicher „Eradikation“ regelmäßig Rezidive auftreten. Bei Patienten mit häufigen Rezidiven wird eine zyklische, präventive Antibiotikagabe empfohlen [108].

\section{Opioide}

Schmerzen gehören zu den häufigsten Symptomen bei Patienten mit CIPO, und ihre Therapie kann schwierig sein. Dennoch darf der Einsatz von Opioiden zur Schmerztherapie bei Patienten mit GITMotilitätsstörungen allenfalls mit großer Zurückhaltung erfolgen, weil diese die Motilitätsstörung und häufig auch die Beschwerden aggravieren [119, 120]. Opioide führen zu sehr starken Veränderungen der gastrointestinalen Motilität mit oft chaotischen Motilitätsmustern und Verlangsamung des intestinalen Transits bereits bei Gesunden [105, 121, 122]. Initial vorhandene oder im Verlauf auftretende funktionelle abdominelle Schmerzen werden bei einem relevanten Prozentsatz von Patienten nicht gebessert, sondern verschlechtert [119, 120, 123]. Entsprechend deletär können die Wirkungen von Opioiden auf den gastrointestinalen Transit und die Symptomatik bei vorbestehender schwerer Motilitätsstörung sein.

\section{Endoskopische und chirurgische Therapie}

Manche Patienten profitieren bezüglich der Schmerzen und der sonstigen Symptomatik von Entlastungsenterostomien, die teils auch endoskopisch möglich sind $[124,125]$. Operationen bei CIPO allgemein und besonders die Resektion betroffener Abschnitte sind demgegenüber fast nie erfolgreich. Solche Eingriffe haben eine hohe Morbidität und Mortalität, und nach 2 Jahren müssen mehr als 50 \% der Überlebenden reoperiert werden [126]. Abdominelle chirurgische Eingriffe während pseudoobstruktiver Phasen sollten auch deshalb möglichst vermieden werden, weil sie das klinische Bild durch (die Möglichkeit der) Bridenbildung komplizieren. Als Ultima Ratio besteht bei Patienten mit schwerem Verlauf und nicht zu tolerierenden Komplikationen der parenteralen Ernährung die Möglichkeit der Dünndarmtransplantation [4-6, 127, 128]. Etwa 20-25\% solcher Transplantationen werden zurzeit bei Patienten mit CIPO durchgeführt. Die 5-Jahres-Überlebensrate liegt bei ca. $70 \%$, die 10-Jahres-Überlebensrate bei etwas mehr als $50 \%$ [129].

\section{Mikrobiom modifizierende Therapien}

Unter der Annahme, dass eine mikrobielle Dysbiose zur Entstehung oder Unterhaltung der Erkrankung beiträgt, wurde in einer Pilotstudie bei einer kleinen Zahl an Patienten mit CIPO ein fäkaler Mikrobiomtransfer durchgeführt. Darunter kam es zu einer geringen Besserung der Symptomatik sowie zur besseren Toleranz oraler Trinksupplemente bzw. einer enteralen Ernährung [130]. Weitere Untersuchungen werden benötigt, bevor Rückschlüsse für die Therapie von CIPO-Patienten gezogen werden können.

Probiotika werden teils in der Therapie von CIPO-Patienten eingesetzt [131], es liegen aber keine Studien zur Wirksamkeit vor.

\section{STATEMENT 13}

Patienten mit ACPO sollen supportiv therapiert werden. [Empfehlungsgrad A, starker Konsens]

\section{STATEMENT 14}

Kommt es unter supportiver Therapie innerhalb von 1-2 Tagen nicht zur deutlichen Besserung oder besteht primär ein schweres Krankheitsbild, soll das Kolon medikamentös (bevorzugte Option) oder endoskopisch dekomprimiert werden. [Empfehlungsgrad A, starker Konsens] 


\section{STATEMENT 15}

Sind alle diese Maßnahmen nicht erfolgreich, kann eine chirurgische Therapie indiziert sein.

[Empfehlungsgrad 0, starker Konsens]

\section{Erläuterungen Statements 13-15}

Trotz zahlreicher Artikel, die das Krankheitsbild beschreiben, gibt es nur wenige qualitativ hochwertige Studien zur Therapie der ACPO. Empfohlen wird die supportive Therapie für alle Patienten (orale Nahrungskarenz, Korrektur von Störungen des Flüssigkeits- und Elektrolythaushalts, Magensonde, rektale Sonde zum Ableiten von Gasen, möglichst Reduktion/Weglassen von motilitätshemmenden Medikamenten, möglichst weitgehende Mobilisation des Patienten) [78, 79]. Sie führt bei der Mehrzahl zur erfolgreichen Behandlung des Krankheitsbildes [132, 133], was mittlerweile auch durch eine prospektive Studie belegt wird [133]. Besonders Patienten mit normaler Kolonwanddicke sprechen in weit mehr als 50 \% der Fälle auf die unspezifische konservative Therapie an [133].

Die Entscheidung zu darüber hinausgehenden medikamentösen, endoskopischen oder chirurgischen Maßnahmen wird anhand des klinischen Verlaufs gestellt. Eine Intensivierung der Therapie ist indiziert bei Patienten, die primär ein sehr weites Kolon haben (Zökum >10-12 cm) oder bei denen die ACPO bereits seit mehr als 3-4 Tagen besteht, sowie bei solchen, die nicht innerhalb von 1-2 Tagen auf die supportiven Maßnahmen ansprechen[78, 79]. Diese Empfehlungen beruhen auf einem allgemeinen Expertenkonsens. Wegen der lebensbedrohlichen Situation, in der sich die Patienten befinden, gibt es keine Studien dazu. Sofern kein Anhalt für Komplikationen besteht, ist bei Patienten mit weitergehendem Interventionsbedarf die medikamentöse Therapie mit Neostigmin zu bevorzugen $[113,134]$, bei Kontraindikationen oder Versagen die endoskopische Dekompression [79, 133]. Chirurgische Therapieoptionen (Zökostomie, Kolon(teil)resektion) kommen nur in Betracht für Patienten, die weiterhin therapierefraktär sind oder Komplikationen (Kolonischämie, Perforation) entwickeln $[47,78,79]$.

\section{STATEMENT 16}

Patienten mit „Slow-Transit“-Obstipation sollten eine ballaststoffreiche Ernährung versuchen, ausreichend Flüssigkeit zuführen und sich ausreichend bewegen.

[Empfehlungsgrad B, starker Konsens]

\section{Erläuterungen}

Diese Empfehlungen entsprechen der Basistherapie bei Obstipation laut S2k-Leitlinie der DGVS [54]. Der positive Effekt von Ballaststoffen auf die Symptomatik wird durch systematische Reviews belegt, allerdings wurden die zugrunde liegenden, randomisierten, kontrollierten Studien nicht an Patienten mit STC durchgeführt, sondern an Patienten mit milder bis mäßiger Obstipation [135]. Aufgrund der schweren Transitstörung ist eine ballaststoffreiche Ernährung bei Patienten mit STC sehr häufig unwirksam und kann gerade bei diesen Patienten auch vermehrt Beschwerden verursachen. In diesem Fall sollte die Zufuhr von Ballaststoffen reduziert werden, und es sollten andere Maßnahmen zur Obstipationstherapie bevorzugt werden [54]. Nur bei Verträglichkeit, aber unzureichendem Effekt einer ballaststoffreichen Ernährung ist es sinnvoll, Ballaststoffe zusätzlich medikamentös zu verabreichen (s. u.).

Eine Verminderung der Trinkmenge unter die empfohlene Tagesmenge reduziert bei Gesunden die Stuhlfrequenz und -menge ohne Beeinflussung des Kolontransits [136]. Entsprechend bestand bei Jugendlichen eine Assoziation zwischen einer niedrigen Trinkmenge und einer niedrigen Stuhlfrequenz [137]. Umgekehrt wurde in Studien gezeigt, dass sich eine Obstipation durch Normalisierung der Trinkmenge bessern lässt [138]. Eine kleine Studie an Gesunden konnte demgegenüber keinen Effekt auf die Stuhlausscheidung bei Steigerung der Trinkmenge über die empfohlene Menge hinaus zeigen [139]. Der fehlende Effekt der übermäßigen Steigerung der Trinkmenge auf die Stuhlausscheidung und das Risiko der Exazerbation einer Obstipation bei Dehydratation werden auch in einer aktuellen systematischen Übersichtsarbeit bestätigt [140].

\section{STATEMENT 17}

Bei unzureichendem Erfolg sollte die Gabe der in > Tab. 16 aufgeführten Medikamente erwogen werden (einzeln oder als Kombination von Präparaten mit unterschiedlichen Wirkprinzipien).

[Empfehlungsgrad B, starker Konsens]

\section{Erläuterungen}

Für alle aufgeführten Wirkstoffe gibt es hochgradige Evidenz (Metaanalysen randomisierter, kontrollierter Studien), die die überlegene Wirksamkeit gegenüber Placebo bei Patienten mit chronischer Obstipation allgemein belegt. Bezüglich der detaillierten Einschätzung der infrage kommenden Medikamente verweisen wir auf die entsprechenden Kapitel der Reizdarm-Leitlinie [2]. Allgemein gilt jedoch, dass Metaanalysen eine moderate bis gute Wirksamkeit bei Obstipation für Ballaststoffe und osmotisch wirksame Laxanzien belegen [141, 142]. Strukturierte Ballaststoffe erzeugen mehr abdominelle Beschwerden als wasserlösliche [146], können aber ebenfalls verwendet werden. PEG-haltige Lösungen haben eine bessere Wirkung und Verträglichkeit als nicht resorbierbare Kohlenhydrate [147]. Der chronische Gebrauch stimulierender Laxanzien wurde durch viele Ärzte gemieden wegen der unbegründeten Annahme, dass diese das Kolon schädigen sowie Abhängigkeit und Gewöhnung fördern. Diese Bedenken sind aber nicht durch Studien belegt [148].

Laxanzien können auch bei STC Stuhlfrequenz und -konsistenz günstig beeinflussen, haben aber keinen Effekt auf abdominelle Schmerzen, Blähungen und das Gefühl der unvollständigen Entleerung [143]. Manche Patienten profitieren von dieser kosteneffektiven Therapie, in schweren Fällen von STC sind Laxanzien jedoch typischerweise unwirksam. 
- Tab. 16 Medikamentöse Therapie bei STC.

\begin{tabular}{|c|c|c|}
\hline Wirkstoff bzw. Wirkstoffgruppe & Evidenz & Kommentar \\
\hline Ballaststoffe & $\begin{array}{l}\text { Metaanalyse randomisierter, kontrollierter Studien } \\
\text { belegt positiven Effekt bei milder bis mäßiger Obsti- } \\
\text { pation, fraglich, ob auch Besserung weiterer Sympto- } \\
\text { me, keine gezielten Studien an Patienten mit STC } \\
\text { [141] }\end{array}$ & $\begin{array}{l}\text { Strukturierte Ballaststoffe werden häufig nicht vertragen, } \\
\text { Ballaststoffe insgesamt sind bei STC sehr häufig unzurei- } \\
\text { chend wirksam (Effekt geringer als bei obstipierten Pa- } \\
\text { tienten mit normalem Transit) }\end{array}$ \\
\hline $\begin{array}{l}\text { Konventionelle Laxanzien } \\
\text { (Makrogole, Bisacodyl, Natriumpi- } \\
\text { cosulfat, Anthrachinone, Lactulose) }\end{array}$ & $\begin{array}{l}\text { Metaanalyse randomisierter, kontrollierter Studien } \\
\text { belegt allgemeine Wirksamkeit in der Behandlung der } \\
\text { Obstipation, nicht speziell STC [142] } \\
\text { Kohortenstudie an Patienten mit STC zeigt Erhöhung } \\
\text { der Stuhlfrequenz, aber keinen Effekt auf assoziierte } \\
\text { Symptome [143] }\end{array}$ & $\begin{array}{l}\text { Lactulose häufig schlecht vertragen (Blähungen!) } \\
\text { Effekt der Laxanzien typischerweise unzureichend bei STC }\end{array}$ \\
\hline Prucaloprid & $\begin{array}{l}\text { Metaanalyse randomisierter, kontrollierter Studien } \\
\text { belegt Wirksamkeit in der Behandlung der Obstipa- } \\
\text { tion allgemein [142] } \\
\text { Integrierte Analyse von } 3 \text { RCT belegt kongruente } \\
\text { Besserung von Transit und Symptomen [144] }\end{array}$ & 5HT4-Agonist, wirkt prokinetisch \\
\hline Linaclotid & $\begin{array}{l}\text { Metaanalyse randomisierter, kontrollierter Studien } \\
\text { belegt Wirksamkeit in der Behandlung der Obstipa- } \\
\text { tion allgemein }[142,145]\end{array}$ & Dosen häufig niedriger als für RDS-C \\
\hline Lubiproston & $\begin{array}{l}\text { Metaanalyse randomisierter, kontrollierter Studien } \\
\text { belegt Wirksamkeit in der Behandlung der Obstipa- } \\
\text { tion allgemein [142] }\end{array}$ & $\begin{array}{l}\text { In verschiedenen europäischen Ländern zugelassen, } \\
\text { derzeit nicht verfügbar }\end{array}$ \\
\hline $\begin{array}{l}\text { Orale } \mu \text {-Opiat-Rezeptor- } \\
\text { Antagonisten }\end{array}$ & $\begin{array}{l}\text { Metaanalyse randomisierter, kontrollierter Studien } \\
\text { belegt positiven Effekt für opiatinduzierte Obstipa- } \\
\text { tion, keine gezielten Studien an Pat. mit STC [104] }\end{array}$ & $\begin{array}{l}\text { In aller Regel nur für Pat. unter Opioidtherapie, die nach } \\
\text { Möglichkeit zu vermeiden ist, können aber Transit auch } \\
\text { bei opioidnaiven Personen beschleunigen [105] }\end{array}$ \\
\hline
\end{tabular}

Die integrierte Analyse von 3 randomisierten, placebokontrollierten Studien konnte aber zeigen, dass Kolontransitzeit und Symptomschwere eindeutig miteinander korrelieren und dass sowohl Transitzeit als auch Beschwerden durch Prucaloprid signifikant reduziert werden [144]. Auch Cholinergika können prokinetisch wirksam sein, haben aber häufig relevante Nebenwirkungen [149]. Für Metoclopramid, Domperidon und Erythromycin konnte kein prokinetischer Effekt am unteren GIT gezeigt werden [150, 151]. Die in manchen Fällen beobachteten positiven Effekte sind möglicherweise durch die Therapie einer begleitenden Transitstörung des Magens oder des proximalen Dünndarms zu erklären.

Der Guanylatzyklase-C-Aktivator Linaclotid ist hocheffektiv in der Therapie der Obstipation [145] und wirkt sich zudem günstig auf Begleitsymptome wie Schmerzen und Blähungen aus [152]. Linaclotid ist in Deutschland nur zur Behandlung des obstipationsprädominanten RDS zugelassen, in den USA hingegen auch für die chronische Obstipation. Die Dosis ist niedriger als beim RDS (145 vs. $290 \mu \mathrm{g}$ ) [153], neuen Studien zufolge könnte die optimale Dosis bei Obstipation jedoch von der ethnischen Zugehörigkeit abhängen [154]. Studien gezielt an Patienten mit STC liegen nicht vor, es wurde aber gezeigt, dass Linaclotid den Kolontransit beschleunigt [155].

Lubiproston ist ein Chlorid-Kanal-Aktivator und bessert Symptomatik und Lebensqualität bei chronischer Obstipation signifikant [142-156]. Das Medikament ist in verschiedenen europä- ischen Ländern zugelassen (https://www.ema.europa.eu/ documents/psusa/lubiprostone-list-nationally-authorised-medici nal-products-psusa/00010290/201607_en.pdf), ist derzeit aber nicht mehr verfügbar.

Probiotika scheinen einen moderaten Effekt auf Stuhlfrequenz und -konsistenz zu haben [157].

PAMORA kommen in aller Regel nur für Patienten unter Opioidtherapie infrage [104], die auch bei STC nach aller Möglichkeit zu vermeiden ist. Im Einzelfall können PAMORA auch zur Beschleunigung des Transits bei opioidnaiven Patienten erwogen werden [105].

Generell gilt, dass Patienten mit STC schlecht, zum Teil auch gar nicht auf die üblichen therapeutischen Maßnahmen ansprechen [50, 61, 62, 158]. Um überhaupt einen relevanten therapeutischen Effekt zu erzielen, sind häufig Kombinationen von 2 oder auch mehr Medikamenten aus unterschiedlichen Wirkstoffgruppen erforderlich (z. B. Laxans plus Prokinetikum). Solche Kombinationstherapien wurden nicht systematisch untersucht, die Empfehlung, Kombinationstherapien für anderweitig therapierefraktäre Patienten zu wählen, bevor invasive Therapieformen erwogen werden, beruht jedoch auf einem breiten Expertenkonsens [54]. Nur für weiterhin therapierefraktäre, streng selektionierte Patienten kommen auch chirurgische Maßnahmen infrage (vgl. Statement 23 mit Kommentar). 


\section{STATEMENT 18}

Bei Patienten mit rektaler Entleerungsstörung sollten als rektale Entleerungshilfen bevorzugt Bisacodyl-Zäpfchen oder CO2 freisetzende Zäpfchen appliziert werden. [Empfehlungsgrad B, starker Konsens]

\section{Erläuterungen}

Die einzigen kontrollierten Studien mit Bisacodyl-Zäpfchen vergleichen 2 Trägersubstanzen bei Patienten mit Querschnittslähmung [159]. An der Wirksamkeit kann kein Zweifel sein, wie unkontrollierte Beobachtungen [160] sowie die Verwendung als Rescue-Medikation in zahlreichen kontrollierten Studien mit neueren Laxanzien belegen. CO2 freisetzende Zäpfchen zeigten in einer randomisierten kontrollierten Studie einen Vorteil gegenüber Placebo [161].

\section{STATEMENT 19}

Patienten, deren Obstipation durch eine Beckenbodendyssynergie verursacht wird, sollten ein Beckenbodentraining erhalten, bevorzugt als Biofeedbacktraining.

[Empfehlungsgrad B, starker Konsens]

\section{Erläuterungen}

Mehrere randomisierte, kontrollierte Studien zeigen einen großen Benefit einer Serie von Biofeedbacksitzungen alle 1-2 Wochen über 2-3 Monate. Dabei besserte sich auch die Stuhlfrequenz $[162,163]$. Patienten mit reiner Slow-Transit-Obstipation profitierten kaum [164], Patienten mit gemischter Ursache der Obstipation teilweise. Auch Metaanalysen berichten über die Effektivität von Biofeedbacktraining bei Beckenbodendyssynergie mit moderater Überlegenheit gegenüber anderen konventionellen Therapieoptionen $[165,166]$. Für eine endgültige Beurteilung sind weitere, gut geplante Studien erforderlich [167]. Dennoch empfehlen amerikanische und europäische Leitlinien die Biofeedbacktherapie klar für die Kurz- und Langzeittherapie bei Beckenbodendyssynergie [168]. Allerdings ist (qualifiziertes) Biofeedbacktraining, das die koordinierte Aktivierung der Bauchpresse bei gleichzeitiger Relaxation des Beckenbodens einübt [169], nicht breit verfügbar. Der Einsatz von Laxanzien, die den Stuhl aufweichen und dadurch die Entleerung erleichtern, oder von Klistieren bzw. CO2 freisetzenden Zäpfchen kann (vorübergehend) unterstützend wirken.

\section{STATEMENT 20}

Bei therapierefraktärer Stuhlentleerungsstörung infolge Beckenbodendyssynergie kann Botox-A injiziert werden. [Empfehlungsgrad C, Konsens]

\section{Erläuterungen}

Bewährt hat sich die endosonografisch gezielte Injektion; der Vorteil gegenüber einer digital-palpatorischen Injektion ist allerdings nicht gezielt untersucht worden. Effekte halten nur wenige Monate an. Der Nutzen einer Langzeitbehandlung mit wiederholten Injektionen wurde nicht untersucht und ist somit unklar [170]. Die Injektion von Botox kann außerdem zur Behandlung analer Spasmen bei Patienten mit M. Hirschsprung nach rektoanaler Durchzugs-OP erwogen werden [171].

\section{STATEMENT 21}

Die sakrale Nervenstimulation (SNS) kann bei konservativ therapierefraktären Fällen einer Slow-Transit-Obstipation (STC) individuell erwogen werden, wobei verlässliche Langzeitdaten fehlen. Patienten mit einer Slow-Transit-Obstipation und gleichzeitiger rektaler Entleerungsstörung scheinen eher vom Effekt der sakralen Nervenstimulation zu profitieren. [Empfehlungsgrad C, starker Konsens]

\section{Erläuterungen}

Dabei handelt es sich um eine Einzelfallentscheidung, bei der auch der Mangel an therapeutischen Alternativen zum Tragen kommt. Eine allgemeine positive Empfehlung kann demgegenüber nicht gegeben werden, zumal 2 größere Studien dazu widersprüchliche Ergebnisse liefern. Einerseits [172] wurde ein fehlender Effekt kurz- und langfristig bei Patienten mit STC gezeigt. Andererseits wurden für Slow- und Normal-Transit-Patienten gute Ergebnisse über 6 Monate gezeigt, die für einen kleinen Teil der Patienten bis zu 5 Jahren anhielten [173]. Dabei sprechen zahlreiche Studien für eine komplexe Beeinflussung afferenter Beckennerven und zentraler Mechanismen [174]. Für die rektale Entleerungsstörung waren nur einzelne Patienten im Rahmen der größeren Studien untersucht worden, in Einzelfällen mit erfolgreicher Therapie.

\section{STATEMENT 22}

Patienten mit M. Hirschsprung sollen chirurgisch therapiert werden.

[Empfehlungsgrad A, starker Konsens]

\section{Erläuterungen}

Die chirurgische Therapie des M. Hirschsprung stellt die Standardtherapie dar und hat das Ziel, das befallene aganglionäre Segment zu resezieren. Sie ist breit anerkannt und in vielen Fällen unumgänglich, sodass es keine vergleichenden Studien zu rein konservativem Vorgehen gibt. Langzeitbeobachtungen zeigen im Vergleich zu alters- und geschlechtsadaptierten Kontrollen postoperativ im Kindesalter eine verminderte Kontrolle über die Stuhlentleerung, die sich aber im Erwachsenenalter bessert. Die allgemeine Lebensqualität ist nicht reduziert, allerdings bei Einschränkungen im emotionalen und sexuellen Bereich [175]. Nach Diagnosestellung eines M. Hirschsprung im Säuglings- bzw. Kleinkindalter können serielle rektale Irrigationen den Darm dekompri- 
mieren, das Auftreten einer Enterokolitis verhindern und deshalb überbrückend eingesetzt werden [176]. Die definitive Therapie in Form einer sogenannten Durchzugsoperation kann bei nicht dilatiertem Kolon in der Regel direkt durchgeführt werden [176179]. In den meisten Fällen liegt ein kurzstreckiger Kolonbefall vor (auf das Rektosigmoid beschränkt), der die Resektion dieses Abschnitts mit koloanaler Anastomose erfordert. Intraoperativ kann mittels Schnellschnitts die Grenze der Aganglionose sehr gut bestimmt werden. Bei mit Hirschsprung assoziierter Enterokolitis oder signifikanter Kolondilatation wird zuerst für einige Monate ein protektives Kolostoma angelegt [180] und meistens 4-6 Monate danach die definitive Operation durchgeführt. Die Komplikationsraten der verschiedenen „Pull-through“-Techniken liegen bei 4-16\% [177, 179, 181, 182]. Die transanale endorektale „Pull-through“-Operationstechnik scheint hinsichtlich Komplikationsraten und funktioneller Ergebnisse gegenüber der transabdominellen „Pull-through“-Operation vorteilhaft zu sein [183]. In sehr seltenen Fällen wird der M. Hirschsprung erst im Erwachsenenalter diagnostiziert. Diese Patienten haben meist nur ein sehr kurzes aganglionäres Segment. Die Behandlungsgrundsätze für Erwachsene unterscheiden sich nicht von denen für Kinder [184, 185].

\section{STATEMENT 23}

Die Indikation zur Kolonresektion bei Obstipation ist besonders sorgfältig zu treffen und soll beschränkt werden auf Patienten mit anderweitig therapierefraktärer STC (subtotale Kolektomie) oder auf Patienten, die therapierefraktäre Beschwerden aufweisen, welche mit umschriebenen morphologischen Veränderungen des Kolons (z. B. IMC) assoziiert sind.

[Empfehlungsgrad A, Konsens]

\section{Erläuterungen}

Es gibt keine Studien, die subtotale Kolektomie versus dauerhafte medikamentöse Therapie verglichen haben. Eine Fragebogenerhebung nach subtotaler Kolektomie zeigt eine Zufriedenheit von 80-90\% [186]. Ungefähr $10 \%$ der Patienten benötigen postoperativ Antidiarrhoika. Niedrigere Erfolgsraten in anderen Studien verdeutlichen die Notwendigkeit der sorgfältigen Patientenselektion für diese Therapieoption [69, 186-188].

\section{STATEMENT 24}

Sekundäre und nicht selbst limitierende Motilitätsstörungen sollten möglichst kausal behandelt werden. Zu Beginn der kausalen Therapie oder falls die zugrunde liegende Störung nicht zu beheben ist, kann eine symptomatische Therapie (Antidiarrhoika oder Laxanzien) erforderlich sein. [Empfehlungsgrad B, starker Konsens]

\section{Erläuterungen}

Es gibt keine etablierten und durch Studien belegten Therapieformen sekundärer Motilitätsstörungen. Eine symptomatische Therapie kann indiziert sein. Die Behandlung der zugrunde liegenden Störung - sofern möglich - bildet aber die sinnvollste und effektivste Therapie.

Interessenkonflikt

Die Interessenkonflikte sämtlicher Autoren finden sich im Leitlinienreport, Anhang D (https://www.dgvs.de/wissen/leitlinien/leitlinien-dgvs/ intestinale-motilitaetsstoerungen/)

\section{Literatur}

[1] Bundesärztekammer (BÄK) KBK, Arbeitsgemeinschaft der Wissenschaftlichen Medizinischen Fachgesellschaften (AWMF). Nationale VersorgungsLeitlinie Neuropathie bei Diabetes im Erwachsenenalter Langfassung. 2011 http://www.diabetes.versorgungsleitlinien.de

[2] Layer P, Andresen V, Pehl C et al. S3-Leitlinie Reizdarmsyndrom: Definition, Pathophysiologie, Diagnostik und Therapie. Gemeinsame Leitlinie der Deutschen Gesellschaft für Verdauungs- und Stoffwechselkrankheiten (DGVS) und der Deutschen Gesellschaft für Neurogastroenterologie und Motilität (DGNM). Z Gastroenterol 2011; 49: 237-293

[3] Phillips BDM, Ball C, Sackett D et al. Oxford Centre for Evidence-based Medicine - Levels of Evidence CEBM. 2009; 2009

[4] Connor FL, Di Lorenzo C. Chronic intestinal pseudo-obstruction: assessment and management. Gastroenterology 2006; 130: S29-\$36

[5] Stanghellini V, Cogliandro RF, de Giorgio R et al. Chronic intestinal pseudo-obstruction: manifestations, natural history and management. Neurogastroenterol Motil 2007; 19: 440-452

[6] Seidl H, Pehl C, Schepp W et al. [Chronic intestinal pseudo-obstruction review and update 2008]. Z Gastroenterol 2008; 46: 704-711

[7] Kessmann J. Hirschsprung's disease: diagnosis and management. Am Fam Physician 2006; 74: 1319-1322

[8] Knowles $\mathrm{CH}$, Lindberg $\mathrm{G}$, Panza E et al. New perspectives in the diagnosis and management of enteric neuropathies. Nat Rev Gastroenterol Hepatol 2013; 10: 206-218

[9] Goldstein AM, Thapar N, Karunaratne TB et al. Clinical aspects of neurointestinal disease: Pathophysiology, diagnosis, and treatment. Dev Biol 2016; 417: 217-228

[10] Furness JB. The enteric nervous system and neurogastroenterology. Nat Rev Gastroenterol Hepatol 2012; 9: 286-294

[11] Knowles CH, De Giorgio R, Kapur RP et al. The London Classification of gastrointestinal neuromuscular pathology: report on behalf of the Gastro 2009 International Working Group. Gut 2010; 59: 882-887

[12] Boeckxstaens G, Camilleri M, Sifrim D et al. Fundamentals of Neurogastroenterology: Physiology/Motility - Sensation. Gastroenterology 2016; 150: 1292-1304

[13] Vanner S, Greenwood-Van Meerveld B, Mawe G et al. Fundamentals of Neurogastroenterology: Basic Science. Gastroenterology 2016; 150: $1280-1291$

[14] De Giorgio R, Camilleri M. Human enteric neuropathies: morphology and molecular pathology. Neurogastroenterol Motil 2004; 16: 515-531

[15] Di Lorenzo C. Pseudo-obstruction: current approaches. Gastroenterology 1999; 116: 980-987

[16] De Giorgio R, Guerrini S, Barbara G et al. New insights into human enteric neuropathies. Neurogastroenterol Motil 2004; 16 (Suppl. 1): 143-147

[17] Brosens E, Burns A], Brooks AS et al. Genetics of enteric neuropathies. Dev Biol 2016; 417: 198-208 
[18] Panza E, Knowles CH, Graziano C et al. Genetics of human enteric neuropathies. Prog Neurobiol 2012; 96: 176-189

[19] De Giorgio R, Guerrini S, Barbara G et al. Inflammatory neuropathies of the enteric nervous system. Gastroenterology 2004; 126: 1872-1883

[20] Smith VV, Gregson N, Foggensteiner L et al. Acquired intestinal aganglionosis and circulating autoantibodies without neoplasia or other neural involvement. Gastroenterology 1997; 112: 1366-1371

[21] Di Nardo G, Blandizzi C, Volta U et al. Review article: molecular, pathological and therapeutic features of human enteric neuropathies. Aliment Pharmacol Ther 2008; 28: 25-42

[22] Knowles CH, De Giorgio R, Kapur RP et al. Gastrointestinal neuromuscular pathology: guidelines for histological techniques and reporting on behalf of the Gastro 2009 International Working Group. Acta Neuropathol 2009; 118: 271-301

[23] Koh S, Bradley RF, French SW et al. Congenital visceral myopathy with a predominantly hypertrophic pattern treated by multivisceral transplantation. Hum Pathol 2008; 39: 970-974

[24] Dewit S, de Hertogh G, Geboes K et al. Chronic intestinal pseudo-obstruction caused by an intestinal inflammatory myopathy: case report and review of the literature. Neurogastroenterol Motil 2008; 20: 343-348

[25] Finsterer ]. Overview on visceral manifestations of mitochondrial disorders. Neth J Med 2006; 64: 61-71

[26] Bassotti G, Villanacci V, Fisogni S et al. Enteric glial cells and their role in gastrointestinal motor abnormalities: introducing the neuro-gliopathies. World J Gastroenterol 2007; 13: 4035-4041

[27] Grubisic V, Verkhratsky A, Zorec R et al. Enteric glia regulate gut motility in health and disease. Brain Res Bull 2018; 136: 109-117

[28] Sharkey KA. Emerging roles for enteric glia in gastrointestinal disorders. J Clin Invest 2015; 125: 918-925

[29] Bassotti G, Villanacci V, Maurer CA et al. The role of glial cells and apoptosis of enteric neurones in the neuropathology of intractable slow transit constipation. Gut 2006; 55: 41-46

[30] Bassotti G, Villanacci V, Cathomas G et al. Enteric neuropathology of the terminal ileum in patients with intractable slow-transit constipation. Hum Pathol 2006; 37: 1252-1258

[31] Bassotti G, Villanacci V, Nascimbeni R et al. Colonic neuropathological aspects in patients with intractable constipation due to obstructed defecation. Mod Pathol 2007; 20: 367-374

[32] Dinning PG, Bampton PA, Andre J et al. Abnormal predefecatory colonic motor patterns define constipation in obstructed defecation. Gastroenterology 2004; 127: 49-56

[33] Iantorno G, Bassotti G, Kogan Z et al. The enteric nervous system in chagasic and idiopathic megacolon. Am J Surg Pathol 2007; 31: 460-468

[34] Sanders KM, Ward SM, Koh SD. Interstitial cells: regulators of smooth muscle function. Physiol Rev 2014; 94: 859-907

[35] Sanders KM, Kito Y, Hwang S] et al. Regulation of Gastrointestinal Smooth Muscle Function by Interstitial Cells. Physiology (Bethesda) 2016; 31: 316-326

[36] Sarna SK. Are interstitial cells of Cajal plurifunction cells in the gut? Am J Physiol Gastrointest Liver Physiol 2008; 294: G372-G390

[37] Yanagida H, Yanase H, Sanders KM et al. Intestinal surgical resection disrupts electrical rhythmicity, neural responses, and interstitial cell networks. Gastroenterology 2004; 127: 1748-1759

[38] De Giorgio R, Sarnelli G, Corinaldesi R et al. Advances in our understanding of the pathology of chronic intestinal pseudo-obstruction. Gut 2004; 53: 1549-1552

[39] lida $\mathrm{H}$, Ohkubo $\mathrm{H}$, Inamori $\mathrm{M}$ et al. Epidemiology and clinical experience of chronic intestinal pseudo-obstruction in Japan: a nationwide epidemiologic survey. J Epidemiol 2013; 23: 288-294

[40] Smout AJ. Recent developments in gastrointestinal motility. Scand ] Gastroenterol Suppl 2006: 25-31
[41] Lindberg G, Tornblom H, Iwarzon M et al. Full-thickness biopsy findings in chronic intestinal pseudo-obstruction and enteric dysmotility. Gut 2009; 58: 1084-1090

[42] Malagelada C, Karunaratne TB, Accarino A et al. Comparison between small bowel manometric patterns and full-thickness biopsy histopathology in severe intestinal dysmotility. Neurogastroenterol Motil 2018; 30: doi:10.1111/nmo.13219

[43] Stanghellini V, Cogliandro RF, De Giorgio R et al. Natural history of chronic idiopathic intestinal pseudo-obstruction in adults: a single center study. Clin Gastroenterol Hepatol 2005; 3: 449-458

[44] Wells Cl, O'Grady G, Bissett IP. Acute colonic pseudo-obstruction: A systematic review of aetiology and mechanisms. World J Gastroenterol 2017; 23: 5634-5644

[45] Ross SW, Oommen B, Wormer BA et al. Acute Colonic Pseudo-obstruction: Defining the Epidemiology, Treatment, and Adverse Outcomes of Ogilvie's Syndrome. Am Surg 2016; 82: 102-111

[46] Bernardi MP, Warrier S, Lynch AC et al. Acute and chronic pseudo-obstruction: a current update. ANZ J Surg 2015; 85: 709-714

[47] Saunders MD. Acute colonic pseudo-obstruction. Best Pract Res Clin Gastroenterol 2007: 21: 671-687

[48] Vanek VW, Al-Salti M. Acute pseudo-obstruction of the colon (Ogilvie's syndrome). An analysis of 400 cases. Dis Colon Rectum 1986; 29: 203-210

[49] Gladman MA, Knowles CH. Novel concepts in the diagnosis, pathophysiology and management of idiopathic megabowel. Colorectal Dis 2008; 10: 531-538; discussion 538-540

[50] Bharucha AE. Constipation. Best Pract Res Clin Gastroenterol 2007; 21: 709-731

[51] Martucciello G. Hirschsprung's disease, one of the most difficult diagnoses in pediatric surgery: a review of the problems from clinical practice to the bench. Eur J Pediatr Surg 2008; 18: 140-149

[52] Heanue TA, Pachnis V. Enteric nervous system development and Hirschsprung's disease: advances in genetic and stem cell studies. Nat Rev Neurosci 2007; 8: 466-479

[53] Henderson D, Zimmer J, Nakamura $\mathrm{H}$ et al. Hirschsprung's disease in twins: a systematic review and meta-analysis. Pediatr Surg Int 2017; 33: 855-859

[54] Andresen VEP, Frieling T, Herold A et al. S2k-Leitlinie Chronische Obstipation: Definition, Pathophysiologie, Diagnostik und Therapie. Gemeinsame Leitlinie der Deutschen Gesellschaft für Neurogastroenterologie und Motilität (DGNM) und der Deutschen Gesellschaft für Verdauungsund Stoffwechselkrankheiten (DGVS) AWMF-Registriernummer: 021/019. Z Gastroenterol 2013; 51: 21

[55] Rao SS, Rattanakovit K, Patcharatrakul T. Diagnosis and management of chronic constipation in adults. Nat Rev Gastroenterol Hepatol 2016; 13 : 295-305

[56] Camilleri M, Ford AC, Mawe GM et al. Chronic constipation. Nat Rev Dis Primers 2017; 3: 17095

[57] Ouyang A, Locke GR $3^{\text {rd }}$. Overview of neurogastroenterology-gastrointestinal motility and functional GI disorders: classification, prevalence, and epidemiology. Gastroenterol Clin North Am 2007; 36: 485-498, vii

[58] Longstreth GF, Thompson WG, Chey WD et al. Functional bowel disorders. Gastroenterology 2006; 130: 1480-1491

[59] Wong SW, Lubowski DZ. Slow-transit constipation: evaluation and treatment. ANZ J Surg 2007; 77: 320-328

[60] Knowles CH, Farrugia G. Gastrointestinal neuromuscular pathology in chronic constipation. Best Pract Res Clin Gastroenterol 2011; 25: 43-57

[61] Bassotti G, Villanacci V. Slow transit constipation: a functional disorder becomes an enteric neuropathy. World J Gastroenterol 2006; 12: 4609-4613

[62] Rao SS. Constipation: evaluation and treatment of colonic and anorecta motility disorders. Gastroenterol Clin North Am 2007; 36: 687-711, x

[63] Bassotti G, Stanghellini V, Chiarioni G et al. Upper gastrointestinal motor activity in patients with slow-transit constipation. Further evidence for an enteric neuropathy. Dig Dis Sci 1996; 41: 1999-2005 
[64] Seidl H, Gundling F, Pehl C et al. Small bowel motility in functional chronic constipation. Neurogastroenterol Motil 2009; 21: 1278-e122

[65] Glia A, Akerlund JE, Lindberg G. Outcome of colectomy for slow-transit constipation in relation to presence of small-bowel dysmotility. Dis Colon Rectum 2004; 47: 96-102

[66] Andromanakos N, Skandalakis P, Troupis T et al. Constipation of anorectal outlet obstruction: pathophysiology, evaluation and management. J Gastroenterol Hepatol 2006; 21: 638-646

[67] Spiller R. Role of motility in chronic diarrhoea. Neurogastroenterol Motil 2006; 18: 1045-1055

[68] Perez de Arce E, Landskron G, Hirsch S et al. Chronic Intestinal Pseudoobstruction: Clinical and Manometric Characteristics in the Chilean Population. J Neurogastroenterol Motil 2017; 23: 273-280

[69] Camilleri M, Bharucha AE, di Lorenzo C et al. American Neurogastroenterology and Motility Society consensus statement on intraluminal measurement of gastrointestinal and colonic motility in clinical practice. Neurogastroenterol Motil 2008; 20: 1269-1282

[70] Keller ], Bassotti G, Clarke J et al. Expert consensus document: Advances in the diagnosis and classification of gastric and intestinal motility disorders. Nat Rev Gastroenterol Hepatol 2018; 15: 291-308

[71] Keller J, Franke A, Storr M et al. Klinisch relevante Atemtests in der gastroenterologischen Diagnostik - Empfehlungen der Deutschen Gesellschaft får Neurogastroenterologie und MotilitÑt sowie der Deutschen Gesellschaft f̊̊r Verdauungs- und Stoffwechselerkrankungen. Z Gastroenterol 2005; 43: 1071-1090

[72] Amiot A, Joly F, Cazals-Hatem D et al. Prognostic yield of esophageal manometry in chronic intestinal pseudo-obstruction: a retrospective cohort of 116 adult patients. Neurogastroenterol Motil 2012; 24: 1008e542

[73] Rao SS, Camilleri M, Hasler WL et al. Evaluation of gastrointestinal transit in clinical practice: position paper of the American and European Neurogastroenterology and Motility Societies. Neurogastroenterol Motil 2011; 23: 8-23

[74] Bertram F, Andresen V, Layer P et al. Simultaneous non-invasive measurement of liquid gastric emptying and small bowel transit by combined 13C-acetate and H2-lactulose breath test. J Breath Res 2014; 8: 046007

[75] Antonucci A, Fronzoni L, Cogliandro L et al. Chronic intestinal pseudoobstruction. World J Gastroenterol 2008; 14: 2953-2961

[76] Pehl C, Enck P, Franke A et al. Empfehlungen zur anorektalen Manometrie im Erwachsenenalter. Z Gastroenterol 2007; 45: 397-417

[77] De Giorgio R, Knowles CH. Acute colonic pseudo-obstruction. Br J Surg 2009; 96: 229-239

[78] Eisen GM, Baron TH, Dominitz JA et al. Acute colonic pseudo-obstruction. Gastrointest Endosc 2002; 56: 789-792

[79] Saunders MD, Kimmey MB. Systematic review: acute colonic pseudoobstruction. Aliment Pharmacol Ther 2005; 22: 917-925

[80] O’Dwyer RH, Acosta A, Camilleri M et al. Clinical Features and Colonic Motor Disturbances in Chronic Megacolon in Adults. Dig Dis Sci 2015; 60: 2398-2407

[81] Camilleri M. New imaging in neurogastroenterology: an overview. Neurogastroenterol Motil 2006; 18: 805-812

[82] Ohkubo H, Masaki T, Matsuhashi N et al. Histopathologic findings in patients with idiopathic megacolon: a comparison between dilated and non-dilated loops. Neurogastroenterol Motil 2014; 26: 571-580

[83] de Lorijn F, Kremer LC, Reitsma JB et al. Diagnostic tests in Hirschsprung disease: a systematic review. J Pediatr Gastroenterol Nutr 2006; 42: 496-505

[84] Friedmacher F, Puri P. Rectal suction biopsy for the diagnosis of Hirschsprung's disease: a systematic review of diagnostic accuracy and complications. Pediatr Surg Int 2015; 31: 821-830
[85] Chen JZ, Jamieson DH, Skarsgard ED. Does pre-biopsy contrast enema delay the diagnosis of long segment Hirschsprung's disease? Eur J Pediatr Surg 2010; 20: 375-378

[86] Frongia G, Gunther P, Schenk JP et al. Contrast Enema for Hirschsprung Disease Investigation: Diagnostic Accuracy and Validity for Subsequent Diagnostic and Surgical Planning. Eur J Pediatr Surg 2016; 26: 207-214

[87] Rao SS, Ozturk R, Laine L. Clinical utility of diagnostic tests for constipation in adults: a systematic review. Am J Gastroenterol 2005; 100 : 1605-1615

[88] An evidence-based approach to the management of chronic constipation in North America. Am J Gastroenterol 2005; 100 (Suppl. 1): S1-S4

[89] Keller J, Layer P. Intestinal and anorectal motility and functional disorders. Best Pract Res Clin Gastroenterol 2009; 23: 407-423

[90] Mion F, Garros A, Brochard C et al. 3D High-definition anorectal manometry: Values obtained in asymptomatic volunteers, fecal incontinence and chronic constipation. Results of a prospective multicenter study (NOMAD). Neurogastroenterol Motil 2017; 29: doi:10.1111/ nmo. 13049

[91] Grossi U, Carrington EV, Bharucha AE et al. Diagnostic accuracy study of anorectal manometry for diagnosis of dyssynergic defecation. Gut 2016; 65: 447-455

[92] Asrani VM, Yoon HD, Megill RD et al. Interventions That Affect Gastrointestinal Motility in Hospitalized Adult Patients: A Systematic Review and Meta-Analysis of Double-Blind Placebo-Controlled Randomized Trials. Medicine (Baltimore) 2016; 95: e2463

[93] Turgeon DK. Domperidone in chronic intestinal pseudoobstruction. Gastroenterology 1990; 99: 1194

[94] Dalgic B, Sari S, Dogan I et al. Chronic intestinal pseudoobstruction: report of four pediatric patients. Turk J Gastroenterol 2005; 16: 93-97

[95] Emmanuel AV, Shand AG, Kamm MA. Erythromycin for the treatment of chronic intestinal pseudo-obstruction: description of six cases with a positive response. Aliment Pharmacol Ther 2004; 19: 687-694

[96] Verne GN, Eaker EY, Hardy E et al. Effect of octreotide and erythromycin on idiopathic and scleroderma-associated intestinal pseudoobstruction. Dig Dis Sci 1995; 40: 1892-901

[97] Emmanuel AV, Kamm MA, Roy AJ et al. Randomised clinical trial: the efficacy of prucalopride in patients with chronic intestinal pseudo-obstruction-a double-blind, placebo-controlled, cross-over, multiple $\mathrm{n}=$ 1 study. Aliment Pharmacol Ther 2012; 35: 48-55

[98] Manini ML, Camilleri M, Grothe R et al. Application of Pyridostigmine in Pediatric Gastrointestinal Motility Disorders: A Case Series. Paediatr Drugs 2018; 20: 173-180

[99] O'Dea C], Brookes JH, Wattchow DA. The efficacy of treatment of patients with severe constipation or recurrent pseudo-obstruction with pyridostigmine. Colorectal Dis 2010; 12: 540-548

[100] Ambartsumyan L, Flores A, Nurko S et al. Utility of Octreotide in Advancing Enteral Feeds in Children with Chronic Intestinal PseudoObstruction. Paediatr Drugs 2016; 18: 387-392

[101] Xu N, Zhao J, Liu J et al. Clinical analysis of 61 systemic lupus erythematosus patients with intestinal pseudo-obstruction and/or ureterohydronephrosis: a retrospective observational study. Medicine (Baltimore) 2015; 94: e419

[102] Raja J, Nihtyanova SI, Murray CD et al. Sustained benefit from intravenous immunoglobulin therapy for gastrointestinal involvement in systemic sclerosis. Rheumatology (Oxford) 2016; 55: 115-119

[103] Flanagan EP, Saito YA, Lennon VA et al. Immunotherapy trial as diagnostic test in evaluating patients with presumed autoimmune gastrointestinal dysmotility. Neurogastroenterol Motil 2014; 26: 1285-1297

[104] Nee J, Zakari M, Sugarman MA et al. Efficacy of Treatments for OpioidInduced Constipation: Systematic Review and Meta-analysis. Clin Gastroenterol Hepatol 2018; 16: 1569-1584.e2 
[105] Kaufman PN, Krevsky B, Malmud LS et al. Role of opiate receptors in the regulation of colonic transit. Gastroenterology 1988; 94: 1351-1356

[106] Di Stefano M, Malservisi S, Veneto G et al. Rifaximin versus chlortetracycline in the short-term treatment of small intestinal bacterial overgrowth. Aliment Pharmacol Ther JID - 8707234 2000; 14: 551-556

[107] Lauritano EC, Gabrielli M, Scarpellini E et al. Antibiotic therapy in small intestinal bacterial overgrowth: rifaximin versus metronidazole. Eur Rev Med Pharmacol Sci 2009; 13: 111-116

[108] Pironi L, Arends ], Bozzetti F et al. ESPEN guidelines on chronic intestinal failure in adults. Clin Nutr 2016; 35: 247-307

[109] Olausson EA, Storsrud S, Grundin $\mathrm{H}$ et al. A small particle size diet reduces upper gastrointestinal symptoms in patients with diabetic gastroparesis: a randomized controlled trial. Am J Gastroenterol 2014; 109: 375-385

[110] Camilleri M, Kerstens R, Rykx A et al. A placebo-controlled trial of prucalopride for severe chronic constipation. N Engl J Med 2008; 358: 2344-2354

[111] Tack J, van Outryve M, Beyens G et al. Prucalopride (Resolor) in the treatment of severe chronic constipation in patients dissatisfied with laxatives. Gut 2009; 58: 357-365

[112] Yiannakou Y, Bouchoucha M, Schiefke I et al. Efficacy and safety of prucalopride in men with chronic constipation: a phase 3, randomized, double-blind, placebo-controlled trial. Gastroenterology 2014; 146: 1

[113] Ponec RJ, Saunders MD, Kimmey MB. Neostigmine for the treatment of acute colonic pseudo-obstruction. N Engl J Med 1999; 341: 137-141

[114] Schang JC, Devroede G. Beneficial effects of naloxone in a patient with intestinal pseudoobstruction. Am J Gastroenterol 1985; 80: 407-411

[115] Wang JL, Liu G, Liu T et al. Intestinal pseudo-obstruction in systemic lupus erythematosus: a case report and review of the literature. Medicine (Baltimore) 2014; 93: e248

[116] Husebye E. The pathogenesis of gastrointestinal bacterial overgrowth. Chemotherapy 2005; 51 (Suppl. 1): 1-22

[117] Lloyd DA, Gabe SM. Managing liver dysfunction in parenteral nutrition. Proc Nutr Soc 2007; 66: 530-538

[118] Sabate JM, Jouet P, Harnois F et al. High prevalence of small intestinal bacterial overgrowth in patients with morbid obesity: a contributor to severe hepatic steatosis. Obes Surg 2008; 18: 371-377

[119] Grunkemeier DM, Cassara JE, Dalton CB et al. The narcotic bowel syndrome: clinical features, pathophysiology, and management. Clin Gastroenterol Hepatol 2007; 5: 1126-1139; quiz 1121-1122

[120] Tuteja AK, Biskupiak J, Stoddard G] et al. Opioid-induced bowel disorders and narcotic bowel syndrome in patients with chronic non-cancer pain. Neurogastroenterol Motil 2010; 22: 424-430, e96

[121] Jeong ID, Camilleri M, Shin A et al. A randomised, placebo-controlled trial comparing the effects of tapentadol and oxycodone on gastrointestinal and colonic transit in healthy humans. Aliment Pharmacol Ther 2012; 35: 1088-1096

[122] Gaskell H, Derry S, Stannard C et al. Oxycodone for neuropathic pain in adults. Cochrane Database Syst Rev 2016; 7: Cd010692

[123] Szigethy E, Knisely M, Drossman D. Opioid misuse in gastroenterology and non-opioid management of abdominal pain. Nat Rev Gastroenterol Hepatol 2018; 15: 168-180

[124] Ohkubo H, Fuyuki A, Arimoto J et al. Efficacy of percutaneous endoscopic gastro-jejunostomy (PEG-J) decompression therapy for patients with chronic intestinal pseudo-obstruction (CIPO). Neurogastroenterol Motil 2017; 29: doi:10.1111/nmo.13127

[125] Tun G, Bullas D, Bannaga A et al. Percutaneous endoscopic colostomy: a useful technique when surgery is not an option. Ann Gastroenterol 2016; 29: 477-480

[126] Sabbagh C, Amiot A, Maggiori L et al. Non-transplantation surgical approach for chronic intestinal pseudo-obstruction: analysis of 63 adult consecutive cases. Neurogastroenterol Motil 2013; 25: e680-e686
[127] Mehendale SR, Yuan CS. Opioid-induced gastrointestinal dysfunction. Dig Dis 2006; 24: 105-112

[128] Panchal SJ, Muller-Schwefe P, Wurzelmann JI. Opioid-induced bowel dysfunction: prevalence, pathophysiology and burden. Int J Clin Pract 2007; 61: 1181-1187

[129] Lauro A, Zanfi C, Pellegrini S et al. Isolated intestinal transplant for chronic intestinal pseudo-obstruction in adults: long-term outcome. Transplant Proc 2013; 45: 3351-3355

[130] Gu L, Ding C, Tian H et al. Serial Frozen Fecal Microbiota Transplantation in the Treatment of Chronic Intestinal Pseudo-obstruction: A Preliminary Study. J Neurogastroenterol Motil 2017; 23: 289-297

[131] Hashizume N, Yagi M, Ushijima K et al. Pharmacotherapy for pediatric chronic intestinal pseudo-obstruction: Nationwide survey in Japan. Pediatr Int 2017; 59: 467-472

[132] Loftus CG, Harewood GC, Baron TH. Assessment of predictors of response to neostigmine for acute colonic pseudo-obstruction. Am J Gastroenterol 2002; 97: 3118-3122

[133] Zhao C, Xie T, Li J et al. Acute Colonic Pseudo-Obstruction with Feeding Intolerance in Critically III Patients: A Study according to Gut Wall Analysis. Gastroenterol Res Pract 2017; 2017: 9574592

[134] van der Spoel Jl, Oudemans-van Straaten HM, Stoutenbeek CP et al. Neostigmine resolves critical illness-related colonic ileus in intensive care patients with multiple organ failure-a prospective, double-blind, placebo-controlled trial. Intensive Care Med 2001; 27: 822-827

[135] Rao SS, Yu S, Fedewa A. Systematic review: dietary fibre and FODMAPrestricted diet in the management of constipation and irritable bowel syndrome. Aliment Pharmacol Ther 2015; 41: 1256-1270

[136] Klauser AG, Beck A, Schindlbeck NE et al. Low fluid intake lowers stool output in healthy male volunteers. Z Gastroenterol 1990; 28: 606-609

[137] Chien LY, Liou YM, Chang P. Low defaecation frequency in Taiwanese adolescents: association with dietary intake, physical activity and sedentary behaviour. J Paediatr Child Health 2011; 47: 381-386

[138] Anti M, Pignataro G, Armuzzi A et al. Water supplementation enhances the effect of high-fiber diet on stool frequency and laxative consumption in adult patients with functional constipation. Hepatogastroenterology 1998; 45: 727-732

[139] Chung BD, Parekh U, Sellin JH. Effect of increased fluid intake on stool output in normal healthy volunteers. J Clin Gastroenterol 1999; 28: 29-32

[140] Wood LN, Markowitz MA, Parameshwar PS et al. Is it Safe to Reduce Water Intake in the Overactive Bladder Population? A Systematic Review. J Urol 2018; 200: 375-381

[141] Yang J, Wang HP, Zhou L et al. Effect of dietary fiber on constipation: a meta analysis. World J Gastroenterol 2012; 18: 7378-7383

[142] Ford AC, Suares NC. Effect of laxatives and pharmacological therapies in chronic idiopathic constipation: systematic review and meta-analysis. Gut 2011; 60: 209-218

[143] Dinning PG, Hunt L, Lubowski DZ et al. The impact of laxative use upon symptoms in patients with proven slow transit constipation. BMC Gastroenterol 2011; 11: 121

[144] Emmanuel A, Cools M, Vandeplassche L et al. Prucalopride improves bowe function and colonic transit time in patients with chronic constipation: an integrated analysis. Am J Gastroenterol 2014; 109: 887-894

[145] Shah ED, Kim HM, Schoenfeld P. Efficacy and Tolerability of Guanylate Cyclase-C Agonists for Irritable Bowel Syndrome with Constipation and Chronic Idiopathic Constipation: A Systematic Review and Meta-Analysis. Am J Gastroenterol 2018; 113: 329-338

[146] Quartero AO, Meineche-Schmidt V, Muris ] et al. Bulking agents, antispasmodic and antidepressant medication for the treatment of irritable bowel syndrome. Cochrane Database Syst Rev 2005: CD003460

[147] Ramkumar D, Rao SS. Efficacy and safety of traditional medical therapies for chronic constipation: systematic review. Am J Gastroenterol 2005; 100: 936-971 
[148] Muller-Lissner SA, Kamm MA, Scarpignato C et al. Myths and misconceptions about chronic constipation. Am J Gastroenterol 2005; 100 : 232-242

[149] Bharucha AE, Low P, Camilleri M et al. A randomised controlled study of the effect of cholinesterase inhibition on colon function in patients with diabetes mellitus and constipation. Gut 2013; 62: 708-715

[150] Bassotti G, Chiarioni G, Vantini I et al. Effect of different doses of erythromycin on colonic motility in patients with slow transit constipation. Z Gastroenterol 1998; 36: 209-213

[151] Dranove J, Horn D, Reddy SN et al. Effect of intravenous erythromycin on the colonic motility of children and young adults during colonic manometry. J Pediatr Surg 2010; 45: 777-783

[152] Lacy BE, Schey R, Shiff S] et al. Linaclotide in Chronic Idiopathic Constipation Patients with Moderate to Severe Abdominal Bloating: A Randomized, Controlled Trial. PLoS One 2015; 10: e0134349

[153] Schoenfeld P, Lacy BE, Chey WD et al. Low-Dose Linaclotide (72 mug) for Chronic Idiopathic Constipation: A 12-Week, Randomized, Double-Blind, Placebo-Controlled Trial. Am J Gastroenterol 2018; 113: 105-114

[154] Fukudo S, Miwa H, Nakajima A et al. Dose-finding study of linaclotide in Japanese patients with chronic constipation: A phase II randomized, double-blind, and placebo-controlled study. Neurogastroenterol Motil 2018; 30: e13442

[155] Andresen V, Camilleri M, Busciglio IA et al. Effect of 5 days linaclotide on transit and bowel function in females with constipation-predominant irritable bowel syndrome. Gastroenterology 2007; 133: 761-768

[156] Fukudo S, Hongo M, Kaneko $\mathrm{H}$ et al. Lubiprostone increases spontaneous bowel movement frequency and quality of life in patients with chronic idiopathic constipation. Clin Gastroenterol Hepatol 2015; 13: 294-301.e5

[157] Mollenbrink M, Bruckschen E. [Treatment of chronic constipation with physiologic Escherichia coli bacteria. Results of a clinical study of the effectiveness and tolerance of microbiological therapy with the E. coli Nissle 1917 strain (Mutaflor)]. Med Klin (Munich) 1994; 89: 587-593

[158] Voderholzer WA, Schatke W, Muhldorfer BE et al. Clinical response to dietary fiber treatment of chronic constipation. Am J Gastroenterol 1997; 92: 95-98

[159] Yi Z, Jie C, Wenyi Z et al. Comparison of efficacies of vegetable oil based and polyethylene glycol based bisacodyl suppositories in treating patients with neurogenic bowel dysfunction after spinal cord injury: a meta-analysis. Turk J Gastroenterol 2014; 25: 488-492

[160] Ruidisch MHH, H.].; König, E. Laxanzien-Langzeittherapie mit Bisacodyl. Wirksamkeit und Verträglichkeit bei Patienten mit Rückenmarkverletzungen. Ärztliche Forschung 1994; 41: 3-8

[161] Lazzaroni M, Casini V, Bianchi Porro G. Role or carbon dioxide-releasing suppositories in the treatment of chronic functional constipation: a double-blind, randomised, placebo-controlled trial. Clin Drug Investig 2005; 25: 499-505

[162] Chiarioni G, Heymen S, Whitehead WE. Biofeedback therapy for dyssynergic defecation. World J Gastroenterol 2006; 12: 7069-7074

[163] Heymen S, Scarlett Y, Jones K et al. Randomized, controlled trial shows biofeedback to be superior to alternative treatments for patients with pelvic floor dyssynergia-type constipation. Dis Colon Rectum 2007; 50 : 428-441

[164] Chiarioni G, Salandini L, Whitehead WE. Biofeedback benefits only patients with outlet dysfunction, not patients with isolated slow transit constipation. Gastroenterology 2005; 129: 86-97

[165] Koh CE, Young C], Young JM et al. Systematic review of randomized controlled trials of the effectiveness of biofeedback for pelvic floor dysfunction. $\mathrm{Br}$ J Surg 2008; 95: 1079-1087

[166] Enck P, Van der Voort IR, Klosterhalfen S. Biofeedback therapy in feca incontinence and constipation. Neurogastroenterol Motil 2009; 21: 1133-1141
[167] Woodward S, Norton C, Chiarelli P. Biofeedback for treatment of chronic idiopathic constipation in adults. Cochrane Database Syst Rev 2014: Cd008486

[168] Rao SS, Benninga MA, Bharucha AE et al. ANMS-ESNM position paper and consensus guidelines on biofeedback therapy for anorectal disorders. Neurogastroenterol Motil 2015; 27: 594-609

[169] Lee HJ, Jung KW, Myung S]. Technique of functional and motility test: how to perform biofeedback for constipation and fecal incontinence. J Neurogastroenterol Motil 2013; 19: 532-537

[170] Emile SH, Elfeki HA, Elbanna HG et al. Efficacy and safety of botulinum toxin in treatment of anismus: A systematic review. World J Gastrointest Pharmacol Ther 2016; 7: 453-462

[171] Han-Geurts IJ, Hendrix VC, de Blaauw I et al. Outcome after anal intrasphincteric Botox injection in children with surgically treated Hirschsprung disease. J Pediatr Gastroenterol Nutr 2014; 59: 604-607

[172] Dinning PG, Hunt L, Patton V et al. Treatment efficacy of sacral nerve stimulation in slow transit constipation: a two-phase, double-blind randomized controlled crossover study. Am J Gastroenterol 2015; 110: 733740

[173] Kamm MA, Dudding TC, Melenhorst ] et al. Sacral nerve stimulation for intractable constipation. Gut 2010; 59: 333-340

[174] Carrington EV, Evers ], Grossi U et al. A systematic review of sacral nerve stimulation mechanisms in the treatment of fecal incontinence and constipation. Neurogastroenterol Motil 2014; 26: 1222-1237

[175] Neuvonen MI, Kyrklund K, Rintala RJ et al. Bowel Function and Quality of Life After Transanal Endorectal Pull-through for Hirschsprung Disease: Controlled Outcomes up to Adulthood. Annals of surgery 2017; 265: 622-629

[176] Coran AG, Teitelbaum DH. Recent advances in the management of Hirschsprung's disease. Am J Surg 2000; 180: 382-387

[177] Weidner BC, Waldhausen JH. Swenson revisited: a one-stage, transanal pull-through procedure for Hirschsprung's disease. J Pediatr Surg 2003; 38: $1208-1211$

[178] Rintala RJ. Transanal coloanal pull-through with a short muscular cuff for classic Hirschsprung's disease. Eur J Pediatr Surg 2003; 13: 181-186

[179] Hadidi A. Transanal endorectal pull-through for Hirschsprung's disease: a comparison with the open technique. Eur J Pediatr Surg 2003; 13: 176180

[180] Langer JC, Durrant AC, de la Torre L et al. One-stage transanal Soave pullthrough for Hirschsprung disease: a multicenter experience with 141 children. Ann Surg 2003; 238: 569-583; discussion 583-585

[181] Tomita R, Ikeda T, Fujisaki S et al. Hirschsprung's disease and its allied disorders in adults' histological and clinical studies. Hepatogastroenterology 2003; 50: 1050-1053

[182] Saleh W, Rasheed K, Mohaidly MA et al. Management of Hirschsprung's disease: a comparison of Soave's and Duhamel's pull-through methods. Pediatr Surg Int 2004; 20: 590-593

[183] Chen Y, Nah SA, Laksmi NK et al. Transanal endorectal pull-through versus transabdominal approach for Hirschsprung's disease: a systematic review and meta-analysis. J Pediatr Surg 2013; 48: 642-651

[184] Hyman PE. Adolescents and young adults with Hirschsprung's disease. Curr Gastroenterol Rep 2006; 8: 425-429

[185] Miyamoto M, Egami K, Maeda S et al. Hirschsprung's disease in adults: report of a case and review of the literature. J Nippon Med Sch 2005; 72: $113-120$

[186] Nyam DC, Pemberton JH, Ilstrup DM et al. Long-term results of surgery for chronic constipation. Dis Colon Rectum 1997; 40: 273-279

[187] Kamm MA, Hawley PR, Lennard-Jones JE. Outcome of colectomy for severe idiopathic constipation. Gut 1988; 29: 969-973

[188] Ripetti V, Caputo D, Greco S et al. Is total colectomy the right choice in intractable slow-transit constipation? Surgery 2006; 140: 435-440 